\title{
Psychological treatment of outpatients with substance use disorders in routine care - attachment style, alliance, and treatment outcome
}

\author{
Ylva Söderberg Gidhagen
}

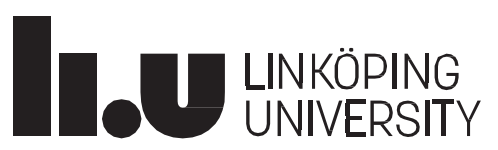

Linköping Studies in Arts and Sciences No. 755

Linköping Studies in Behavioural Science No. 212

Faculty of Arts and Sciences

Linköping 2018 
Linköping Studies in Arts and Sciences • No. 755

Linköping Studies in Behavioural Science $\cdot$ No. 212

At the Faculty of Arts and Sciences at Linköping University, research and doctoral studies are carried out within broad problem areas. Research is organized in interdisciplinary research environments and doctoral studies mainly in graduate schools. Jointly, they publish the series Linköping Studies in Arts and Sciences. This thesis comes from the Division of Psychology at the Department of Behavioural Sciences and Learning.

Distributed by:

Department of Behavioural Sciences and Learning

Linköping University

SE-581 83 Linköping

Ylva Söderberg Gidhagen

Psychological treatment of outpatients with substance use disorders in routine care

- attachment style, alliance, and treatment outcome

Edition 1:1

ISBN 978-91-7685-197-5

ISSN 0282-9800

ISSN1654-2029

@Ylva Söderberg Gidhagen

Department of Behavioural Sciences and Learning, 2018

Printed by: LiU-tryck, Linköping 2018 
To the memory of Emanuel 


\section{Abstract}

Background: Substance use disorder is one of the most important threats to health and welfare in the world. More knowledge is needed about the outcomes of treatments in routine care for patients with substance use disorders (SUDs). These patients often suffer from psychological distress in addition to substance use disorders.

Aims: To evaluate the effects of community-based psychological treatment on SUD outpatients' psychological distress and substance use, and also to analyze the importance of their attachment style and the alliance with regard to treatment outcome.

Methods: Patients who were referred or self-referred to a social worker or a psychotherapist at three outpatient treatment centers for SUD were invited to participate in the study. At each session the patients filled out an instrument measuring psychological distress, the Clinical Outcomes in Routine Evaluation - Outcome Measure (CORE-OM) and to evaluate the alliance to the therapist the Working Alliance Inventory - short form revised (WAI-SR). At treatment start and end the patient filled out the Alcohol Use Disorders Identification Test (AUDIT), the Drug Use Disorders Identification Test including the extended version (DUDIT/DUDIT-E) and the Experiences in Close Relationships - short form (ECR-S) categorizing attachment style. Therapists filled out the CORE Therapy Assessment form at treatment start and the End of Therapy form at treatment termination. After each session, they also filled out the Working Alliance Inventory - short form for therapists (WAI-S).

Results: Of the 119 patients who agreed to participate in the study, there were 100 patients who filled out two or more CORE-OM and WAI-SR forms. Outcome on substance use as measured with AUDIT-C and DUDIT-C was collected for 63 patients. The analyses showed that CORE-OM mean scores were significantly improved. In total $14 \%$ of the patients were recovered, $10 \%$ improved and 5\% deteriorated. AUDIT-C and DUDIT-C mean scores were significantly improved for patients using alcohol and for patients using illicit drugs, respectively.

An insecure attachment style was more common among the patients in this research project, compared to non-clinical groups. The patients with a fearful attachment style scored higher on psychological distress than the patients with a secure attachment style. The associations between the attachment dimensions and psychological distress were stronger than those between attachment and SUD. The causal relationship between attachment style and psychological distress is, however, not clear and can likely go in both directions. Significantly more patients had a secure attachment style at treatment end.

Previous studies have found that the associations between alliance and outcome for SUD patients may be weaker than for other clinical groups, which was confirmed in this thesis. Three moderators of the alliance-outcome association - type of substance use, attachment style and treatment orientation - were assessed. None of the potential moderators tested showed any effect on the association between alliance and psychological distress. The variance among the therapies concerning the session-to-session alliance-outcome association was considerable, indicating that other moderating variables might be found. 
Conclusions: Routine psychological treatment had positive effects on psychological distress as well as on reduction of substance use. However, a substantial number of patients remained unchanged, particularly regarding psychological distress. Among patients with SUD there seems to be a strong relationship between attachment style and psychological distress. Knowledge of the patient's attachment style may help the therapist to tailor the treatment to the patient's needs. A change from an insecure to a secure attachment style can be an important goal for SUD treatment, as it may prevent the patient from using strategies involving substance use for regulating emotions and interpersonal relationships. This thesis confirms and strengthens the finding of a weaker association between alliance and outcome for SUD patients, compared to other clinical groups. A challenge for further research is to find factors that contribute to the allianceoutcome association among SUD patients.

Studies with larger patient groups, additional instruments and methods are needed to develop treatments for SUD patients in routine care.

\section{Svensk sammanfattning}

Substansbrukssyndrom utgör ett av de allvarligaste hoten mot hälsa och välstånd i världen. Det behövs mer kunskap om effekterna av de behandlingar som erbjuds patienter med substansbrukssyndrom i den kliniska vardagen. Dessa patienter lider ofta av psykologiska besvär, utöver själva substansbrukssyndromet.

Målsättningen med denna avhandling har varit att utvärdera effekterna av psykologisk behandling för patienter med substansbrukssyndrom i öppenvård avseende psykologiska problem och substansbruk, samt att analysera betydelsen av patienternas anknytningsstil och alliansen mellan patient och behandlare.

Till studien inbjöds patienter som remitterats eller själva sökt psykologisk behandling hos en socialarbetare eller psykoterapeut vid tre öppenvårdsmottagningar för substansbrukssyndrom. De patienter som accepterade att delta fick vid varje behandlingstillfälle fylla i ett formulär som mäter psykologiska besvär, CORE-OM, samt WAI-SR, som mäter den allians som patienten upplever med sin behandlare. Vid första och sista behandlingstillfället fick patienten också fylla i AUDIT-formuläret som mäter problem relaterade till alkohol, DUDIT-formuläret som mäter problem relaterade till användning av droger samt ECR-S-formuläret som mäter erfarenheten av en aktuell nära relation, vilken kan klassificeras som anknytningsstil. Terapeuten fyllde vid behandlingens början i CORE bedömningsformulär samt efter sista behandlingstillfället det avslutningsformulär som också ingår i CORE. Terapeuten fyllde vid varje behandlingstillfälle i sin egen skattning av alliansen med patienten (WAI-S).

Av det totalt 119 patienter som accepterade att delta i studien, fyllde 100 patienter i minst två CORE-OM- och WAI-SR-formulär, vilket möjliggjorde en mätning av den förändring som behandlingen medfört avseende psykologiska besvär. Vad gäller effekter på substansbruket kunde detta göras för 63 patienter som fyllt i AUDIT-C och DUDIT-C vid både start och slut av behandlingen, frågor om aktuellt substansbruk. Vad gäller psykologiska besvär visade studien efter sista behandlingstillfället en signifikant förbättring av CORE-OM-poängen, med total $14 \%$ av patienterna botade och $10 \%$ reliabelt förbättrade. En reliabel försämring konstaterades för 5\% av patienterna. 
Medelvärdet av både alkoholkonsumtion och bruk av droger minskade signifikant och med stark effekt vid behandlingens slut.

En otrygg anknytningsstil var mer vanlig hos patienterna i studien jämfört med ickekliniska grupper. De patienter som i självskattningsformuläret uppvisade en desorganiserad anknytningsstil hade också högre poäng vad gäller psykologiska besvär, jämfört med de som vid behandlingsstart hade en trygg anknytningsstil. Sambandet mellan anknytningsstil och psykologiska besvär var också starkare än det mellan anknytningsstil och substansbrukssyndrom. Orsakssambandet mellan anknytningsstil och psykologiska besvär är dock inte utrett och kan troligen gå i båda riktningarna. Signifikant fler patienter hade vid behandlingens slut en trygg anknytningsstil.

Tidigare studier har funnit att i terapier med substansbrukssyndrom är sambandet mellan allians och behandlingsutfall svagare jämfört med andra kliniska grupper, vilket bekräftades i den här avhandlingen. Tre moderatorer - typ av substansbruk, anknytningsstil och behandlingsinriktning - utvärderades avseende deras påverkan på relationen mellan allians och behandlingsutfall. Ingen av de potentiella moderatorerna uppvisade någon effekt på relationen mellan allians och utfall avseende psykologiska besvär. Dock fanns det betydande skillnader mellan olika patienter när det gällde sambandet mellan allians och utfall från en session till nästa, något som indikerar att andra moderatorer av betydelse skulle kunna finnas.

Sammanfattningsvis visade studien att psykologisk behandling i den kliniska vardagen av patienter med substansbrukssyndrom gav positiva effekter både på psykologiska besvär och på substansbruk. En avsevärd del av patienterna var emellertid oförändrade, framförallt avseende psykologiska besvär. För patienter med substansbrukssyndrom verkar det finnas en stark relation mellan anknytningsstil och psykologiska besvär. Kunskap om patientens anknytningsstil kan hjälpa terapeuten att utforma en behandling utifrån patientens behov. En förändring från otrygg till trygg anknytningsstil kan vara ett viktigt mål för behandling av substansbrukssyndrom, då det kan få patienten att avstå från strategier där substansbruk används för att hantera känslomässig stress, reglera affekter och interpersonella relationer. Studien bekräftar och stärker också slutsatsen att sambandet mellan allians och behandlingsutfall är svagare för patienter med substansbrukssyndrom jämfört med andra patientgrupper. En utmaning för framtida studier är att identifiera faktorer som bidrar till relationen mellan allians och behandlingsutfall för patienter med substansbrukssyndrom.

Studier med större patientgrupper, fler mätinstrument och metoder är nödvändiga för att utveckla behandlingar i den kliniska vardagen för patienter med substansbrukssyndrom. 


\section{List of papers}

I. Gidhagen, Y., Philips, B., \& Holmqvist, R. (2017). Outcome of psychological treatment of patients with substance use disorders in routine care. Journal of Substance Use, 22, 343-352. https://doi.org/10.1080/14659891.2016.1200149

II. Gidhagen, Y., Holmqvist, R., \& Philips, B. (2018). Attachment style among outpatients with substance use disorders in psychological treatment. Psychology and Psychotherapy: Theory, Research and Practice. https://doi.org/10.1111/papt.12172

III. Gidhagen, Y., Philips, B., \& Holmqvist, R. (manuscript). Moderators of the allianceoutcome association in psychological treatment of substance use disorder outpatients. 


\section{Abbreviations}

AA

AAI

ADHD/ADD

ANCOVA

ANOVA

AUD

AUDIT

AUDIT-C

CALPAS

CAN

CBT

CoM

CORE-OM

CRA

DRD4

DSM-IV

DSM-5

DUDIT

DUDIT-C

DUDIT-E

DUDIT-Ed

ECR

ECR-S

GABA

HAq

IBCT

ICD-10

ITP

IWM

MAO

MATRIX

MET

MI

NA

NIAAA

NIDA

NT

PDT

PRIME

PTSD

RCI

RCT

RF

RP

SAMSHA
Alcoholics Anonymous

Adult Attachment Interview

Attention Deficit Hyperactivity Disorder/Attention Deficit Disorder

ANalysis of COVAriance

ANalysis Of Variance

Alcohol Use Disorder

Alcohol Use Disorders Identification Test

Alcohol Use Disorders Identification Test - Consumption

California Psychotherapy Alliance Scale

Swedish Council for Information on Alcohol and Other Drugs

(In Swedish: Centralförbundet för Alkohol- och Narkotikaupplysning)

Cognitive Behavioral Therapy

Contingency Management

Clinical Outcomes in Routine Evaluation - Outcome Measure

Community Reinforcement Approach

Dopamine Receptor $\mathrm{D}_{4}$

Diagnostic and Statistical Manual of Mental Disorders $-4^{\text {th }}$ Edition

Diagnostic and Statistical Manual of Mental Disorders $-5^{\text {th }}$ Edition

Drug Use Disorders Identification Test

Drug Use Disorders Identification Test - drug use (Consumption)

Drug Use Disorders Identification Test - Extended version

Drug Use Disorders Identification Test - Extended version (part of questionnaire indicating which drugs are used)

Experiences in Close Relationships

Experiences in Close Relationships - Short form

beta-aminobutyric acid (neurotransmitter)

Helping Alliance questionnaire

Integrative Behavioral Couple Therapy

International Statistical Classification of Diseases and Related Health Problems $-10^{\text {th }}$ Revision

Interactional Therapy

Internal Working Models

monoamine oxidase (a family of enzymes)

Intensive Outpatient Alcohol \& Drug Treatment Program

Motivational Enhancement Therapy

Motivational Interviewing

Narcotics Anonymous

National Institute of Alcohol Abuse and Alcoholism

National Institute of Drug Abuse

Network Therapy

Psychodynamic Therapy

Plans - Responses - Impulses - Motives - Evaluations

Post-Traumatic Stress Disorder

Reliable Change Index

Randomized Controlled Trial

Reflective Functioning

Relapse Prevention

Substance Abuse and Mental Health Services Administration 
SBNT

SMH

SOU

SPSS

SUD

TSF

VPPS

WAI-S

WAI-SR

WHO
Social Behavior and Network Therapy

Self-Medication Hypothesis

Swedish Government Official Reports

(In Swedish: Statens Offentliga Utredningar)

The Statistical Package for the Social Sciences

Substance Use Disorder

Twelve Step Facilitation

Vanderbilt Psychotherapy Process Scale

Working Alliance Inventory - Short form

Working Alliance Inventory - Short form Revised

World Health Organization 


\section{Table of contents}

Foreword .................................................................................................................. 1

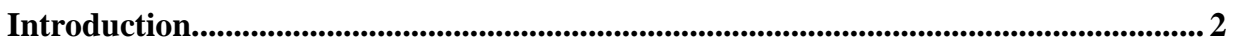

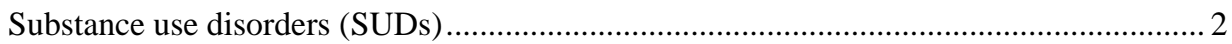

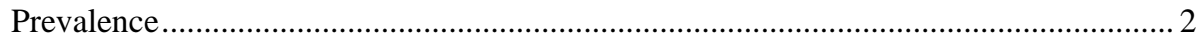

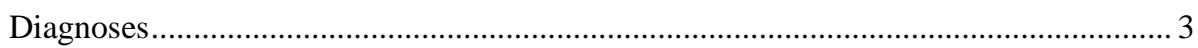

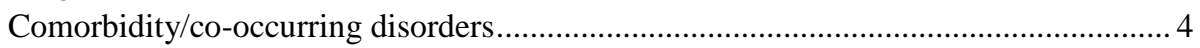

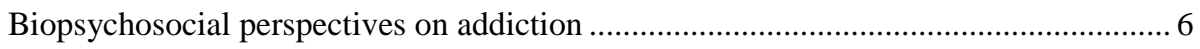

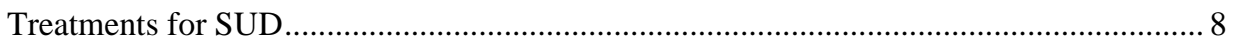

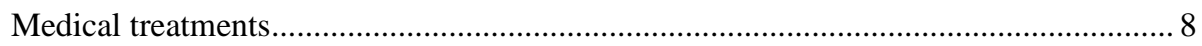

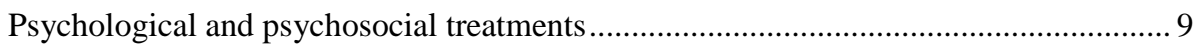

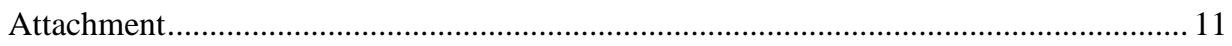

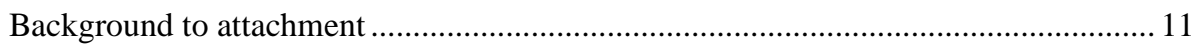

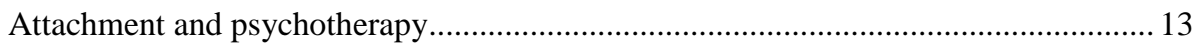

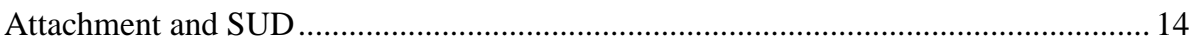

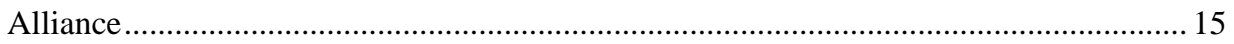

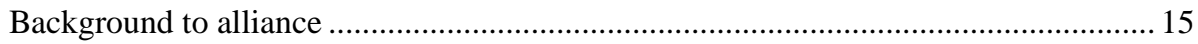

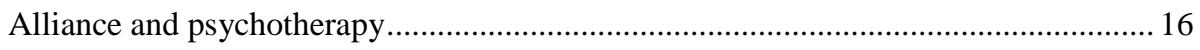

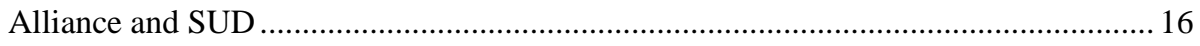

Summary of present knowledge and research questions to address ............................... 18

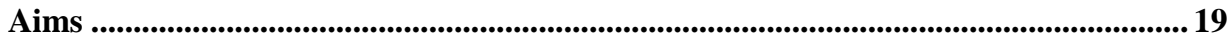

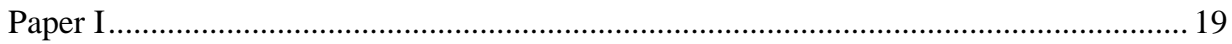

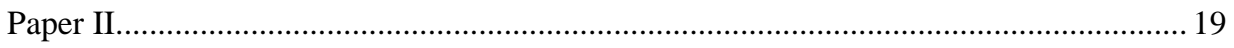

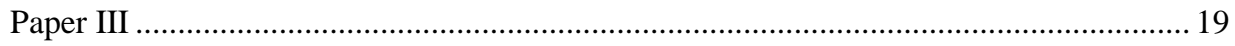

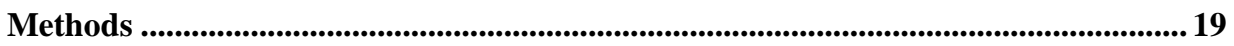

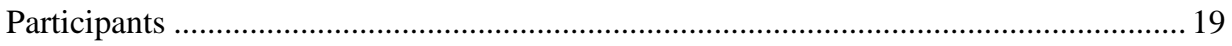

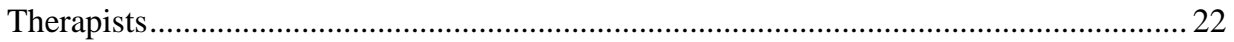

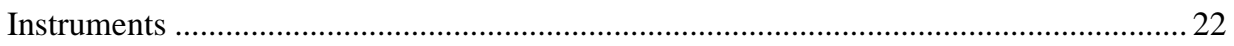

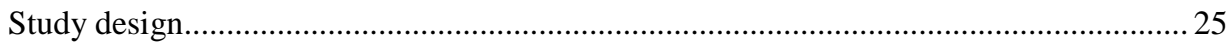

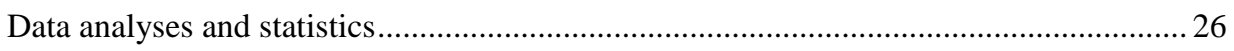

Summary of the results of the included studies .............................................................26

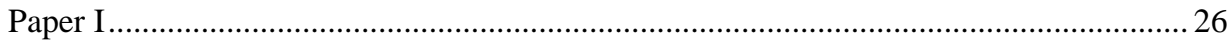

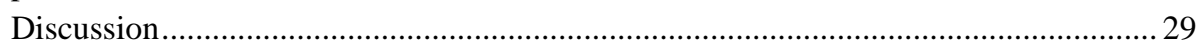

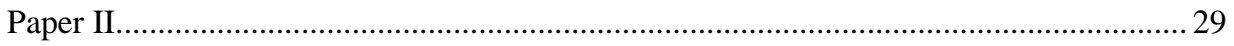

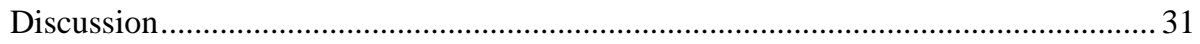

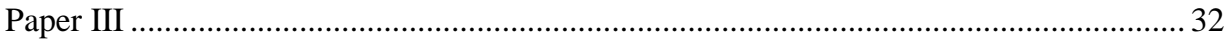

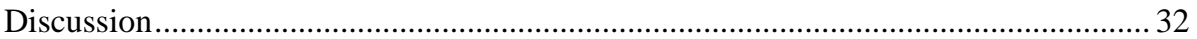

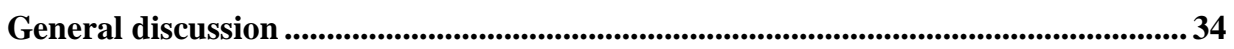

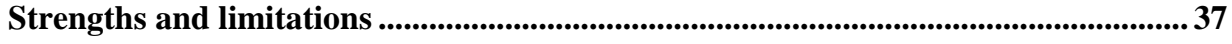

Clinical implications and future perspective............................................................38 
Acknowledgements ..................................................................................................................................... 39

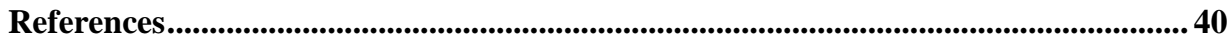

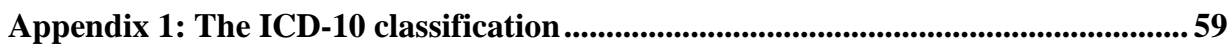

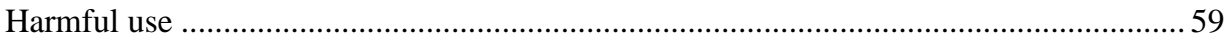

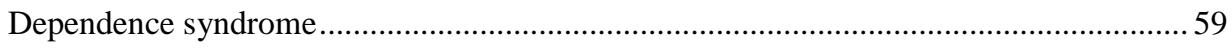

Appendix 2: The DSM-IV classification ................................................................60

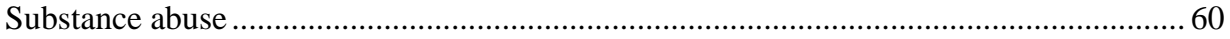

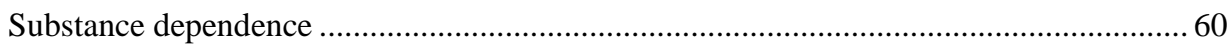

Appendix 3: The four attachment styles............................................................................. 62 



\section{Foreword}

The idea for this thesis arose after 15 years of working with psychotherapy for patients with substance use disorder (SUD). During these years, I had from time to time fascinating, difficult, developing and even exhausting meetings with all these individuals, and heard how they began to misuse substances and how they eventually left substance misuse behind. Sometimes they relapsed, then new meetings, another relapse, new meetings... I wanted to learn more about the importance of the psychological treatment for these patients, the relationship between patient and therapist, and the outcome of this collaborative work. I discussed many of these issues and thoughts with Rolf Holmqvist, my supervisor for my clinical practice of psychotherapy. It happened that he had just finished a treatment outcome study of psychological treatment in primary care and was about to start a similar study for outpatients in psychiatric care. From there we came to discuss the possibility of using a similar approach for evaluating the outcome of psychological treatments for SUD outpatients, with possibilities for comparisons.

I was able to get funding for a pilot project and later the research project itself, with a design aimed at evaluating both psychological distress and substance use, and involving measures of alliance and attachment orientation. The most difficult task turned out to be recruiting outpatient centers. However, data collection started 2011 at three outpatient SUD treatment centers. I was later accepted as a doctoral student at the Department of Behavioural Sciences and Learning at Linköping University.

When we started the analyses of the data collected for about 100 patients, we found it appropriate to plan for three papers. The first focused on reporting outcomes of substance use and psychological distress, the second on studying the attachment styles of SUD patients and the third on the patient-therapist alliance. This thesis includes the three papers (two published and one in manuscript), with some supplementary material added. 


\section{Introduction}

The focus of this thesis is on studying the psychological treatment of substance use disorder outpatients in routine care. It is based on data collected from two municipal outpatient centers for SUD and one outpatient unit for dependency disorders within a county council in Sweden. The aim was to analyze the outcome of SUD treatments, where outcome refers principally to substance use and psychological distress. Identifying potential predictors and moderators associated with outcome has also been of interest.

This introduction gives an overview of important concepts and current research related to the three papers included in the thesis, based on the same data sample but addressing three different aspects: the outcomes of substance use and psychological distress, the role of attachment styles in SUD treatments and the role of the patient-therapist alliance in relation to treatment outcome.

\section{Substance use disorders (SUDs)}

\section{Prevalence}

In a study of the Swedish population (17-84 years), $4.2 \%$ met the criteria for alcohol dependence $(3.0 \%$ of the women and $5.5 \%$ of the men) and $1.7 \%$ abused alcohol $(1.3 \%$ of the women and $2.1 \%$ of the men) according to DSM-IV (Ramstedt, Sundin, Landberg, \& Raninen, 2014). This corresponds to 318000 dependent individuals and 128000 individuals with abuse. In 2017, the consumption of pure alcohol in Sweden was about 9 liters per individual aged 15 or older (Trolldal, \& Leifman, 2018). An estimation shows that one in five children in Sweden - about 385000 - lives in a family where at least one adult has harmful use of alcohol (SOU 2011:6, 2011).

There is no solid information about individuals using illicit drugs in Sweden. A national survey performed in 2012 estimated that 45000 individuals (17-84 years) showed signs of drug dependence during the past 12 months. This corresponds to $0.6 \%$ of the population in the age interval. The estimation is based on answers corresponding to the criteria in DSM-IV. In the same study, the estimation of drug misuse was $0.1 \%$, corresponding to 10000 individuals. These data supposedly indicate minimal levels (Ramstedt et al., 2014). The estimation of individuals using not-prescription drugs is $45000-65000$ and 10000 using doping (SOU 2011:6, 2011; Ramstedt et al., 2014).

The Swedish Council for Information on Alcohol and Other Drugs (CAN) reported that of those who have tried illicit drugs, 60-70\% have only used cannabis (CAN, 2014). The second most commonly used drug is amphetamine. However, if the use of spice and similar new synthetic substances - illegal or legal - is added together, these are used more than any other "classic" illicit drug except for cannabis. The mortality rate in Sweden caused by drugs in 2016 was 908 individuals (Public Health Agency of Sweden) and the corresponding rate for an alcohol-related diagnosis was 1920 individuals (National Board of Health and Welfare, 2017). The link between suicide and mental disorders, particularly for depression and alcohol use disorders, is well established in high-income countries (World Health Organization, 
2018). Up to $40 \%$ of patients seeking treatment for substance dependence reported a history of suicide attempt(s) (Yuodelis-Flores \& Ries, 2015).

\section{Diagnoses}

There are two diagnostic systems in use for mental disorders: the International Classification of Diseases (ICD-10; World Health Organization, 1992) and the Diagnostic and Statistical Manual of Mental Disorders (DSM-5; American Psychiatric Association, 2013). In Sweden, the ICD system is applied for medical records of all diseases. For psychiatric care including substance use disorders, both classification systems are used. They overlap each other partly. However, the previous version of DSM (i.e. DSM-IV; American Psychiatric Organization, 2000) overlapped more with the ICD system. There are some important changes from DSM-IV to DSM-5: the terms abuse and dependence have been replaced with the term substance use disorder, and the disorder is considered to exist in a continuum and not as before in a hierarchical structure. Each specific substance is addressed as a separate use disorder (e.g. alcohol use disorder), but nearly all substances are based on the same overarching criteria. The criteria in DSM-5 have been strengthened. Whereas a diagnosis of substance abuse previously required only one symptom, mild substance use disorder in DSM5 requires two or three symptoms. Craving has been added and the criterion about legal problems has been removed.

There are 11 criteria for an SUD diagnosis, and the number of criteria fulfilled during the same 12-month period decides the severity of the disorder. Thus, two or three criteria indicate a mild substance use disorder, four or five indicate a moderate substance use disorder, and six or more indicate a severe substance use disorder. The symptoms are cognitive, behavioral and physiological. These are the criteria in DSM-5:

1. Taking the substance in larger amounts or for longer than you meant to

2. Wanting to cut down or stop using the substance but not managing to

3. Spending a lot of time getting, using, or recovering from use of the substance

4. Cravings and urges to use the substance

5. Not managing to do what you should at work, home, or school because of substance use

6. Continuing to use, even when it causes problems in relationships

7. Giving up important social, occupational, or recreational activities because of substance use

8. Using substances again and again, even when it puts you in danger

9. Continuing to use, even when you know you have a physical or psychological problem that could have been caused or made worse by the substance

10. Needing more of the substance to get the effect you want (tolerance)

11. Development of withdrawal symptoms, which can be relieved by taking more of the substance

The ICD-10 and DSM-IV classification systems are found in Appendices 1 and 2.

The responsibility for SUD treatment in Sweden is shared by the central government, the county councils, and the municipalities. The municipalities' social services cannot normally 
provide a diagnosis according to ICD-10 or DSM-IV/5 for SUD patients. The Swedish national guidelines for SUD treatment (Socialstyrelsen, 2017) recommend the two questionnaires AUDIT and DUDIT for identifying persons with problems related to alcohol and drugs. They can be used for a classification similar to the ICD-10 and DSM-IV/5 diagnoses. AUDIT and DUDIT were used in this study and are described in the Methods section.

Since the term substance use disorder, first introduced in DSM-5, is replacing substance abuse and substance dependence from DSM-IV and the terms harmful use and dependence syndrome from ICD-10, there will be a mixed terminology in this thesis. The term originally used, e.g. by the authors of different cited publications, has been given. Some authors also prefer the term substance misuse instead of substance abuse.

\section{Comorbidity/co-occurring disorders}

There are four etiological pathways to explain comorbidity or of SUD and mental disorders: genetic or environmental causes, mental disorders leading to the onset of substance abuse, substance abuse causing mental disorders, and finally a bidirectional pathway with interactional effects between substance abuse and mental disorders (Mueser, Drake, \& Wallach, 1998). However, a review of 75 years of comorbidity research, following psychosocial and biological/genetic approaches, shows that there is still a way to go to reach a general and merged etiological model or models (Kushner, 2014).

The importance of comorbidity among SUD patients has been shown in international prevalence studies of the general population and clinical groups, outside the Nordic countries. A summarized conclusion of their results has been given by Öjehagen (2011):

- Persons affected by abuse/dependence have a clearly enhanced risk of developing psychiatric/ personality disorders, and vice versa.

- There is a higher prevalence of psychiatric disorders for those with more severe substance use (dependence versus abuse).

- There is a higher prevalence of psychiatric/personality disorders among persons abusing/dependent on drugs, compared to persons abusing/dependent on alcohol.

- Women with abuse/dependence have a higher prevalence of psychiatric disorders compared to men.

The few studies that have been carried out in the Nordic countries show similar results. Comorbidity also exists for SUD and somatic diseases, but will not be discussed further in this thesis.

Patients undergoing routine treatment for SUD often present extensive psychological distress. About one third of the individuals with alcohol use disorders and about half of those with drug-related disorders suffer from at least one additional mental disorder (e.g. Mertens, Parthasarathy, Moore, \& Weisner, 2003; Regier et al., 1990; Grant et al., 2004).

There is a strong consensus that SUD and depression co-occur and that these problems may be risk factors in both directions. The comorbidity of SUD and anxiety disorders is also 
high, especially among those with an alcohol use disorder (Grant et al., 2004; Boschloo et al., 2011). A Swedish practice-based study found a high (88\%) prevalence of psychological problems among SUD patients in psychotherapy, in particular depression, anxiety, and personality disorders (Philips, 2009). The Drug Abuse Treatment Outcome Study (DATOS) indicated that $39 \%$ of a sample $(n=7402)$ in treatment-seeking individuals with drug dependence met the diagnostic criteria for antisocial personality disorder (Flynn, Craddock, Luckey, Hubbard, \& Dunteman, 1996).

Among adolescents with SUD the rate for comorbidity is 50-90\% (Rowe, Liddle, Greenbaum, \& Henderson, 2004), and the most prevalent disorders are conduct disorder (32$59 \%$ ) and mood disorder (35-61\%) (Wise, Cuffe, \& Fischer, 2001). These adolescents start with substance use earlier, and have greater frequency of use and more chronic use than those with only SUD (Bender, Springer, \& Kim, 2006).

One in four persons with major depression has a substance use disorder (Kessler, 2004). About half of individuals with a lifetime mental disorder have an alcohol or drug use disorder (e.g. Mertens et al., 2003; Regier et al. 1990; Grant et al., 2004). Even higher rates (50-90\%) of co-occurring disorders among patients undergoing mental health or SUD treatment have been reported (Adamson, Todd, Sellman, Huriwai, \& Porter, 2006; Castel, Rush, Urbanoski, \& Toneatto, 2006; Langås, Malt, \& Opjordsmoen, 2012).

For individuals with borderline personality disorder the median prevalence for SUD is $67 \%$, and in individuals with SUD $18 \%$ are diagnosed with borderline personality disorder (Van den Bosch, Verheul, Schippers, \& Van den Brink, 2002). In psychotic disorders the lifetime prevalence is $40-60 \%$ for SUD (Regier et al., 1990). Lifetime rates for individuals with bipolar disorders and SUD ranged from 14\% to 65\% (Sherwood Brown, Suppes, Adinoff, \& Rajan Thomas, 2001).

High rates of co-morbid post-traumatic stress disorders (PTSD) and SUD have been reported in a number of epidemiological studies. Nearly half of the individuals with PTSD also met criteria for an SUD and more than one-in-five met criteria for substance dependence (McCauley, Killeen, Gros, Brady, \& Back, 2012). The rates for trauma exposure for SUD patients were extremely high, at 89-97\% (Quimette, Read, \& Brown, 2005; Gielen, Havermans, Tekelenburg, \& Jansen, 2012; Reynolds et al., 2005; Dansky, Saladin, Coffey, \& Brady, 1997). Most studies suggest that the exposure to traumatic events and PTSD symptoms precede the development of SUD and give support to the self-medication hypothesis (SMH) (Stewart, 1996; Khantzian, 1997).

Attention deficit hyperactivity disorder/attention deficit disorder (ADHD/ADD) in childhood implies a higher risk of SUD as an adult and is most prevalent in combination with conduct disorder or oppositional defiant disorder. The rates for SUD are 50\% for adults with ADHD/ADD (Sullivan \& Rudnik-Levis, 2001) and the prevalence for ADHD/ADD is 14$23 \%$ in SUD populations (Van Emmerik-van Oortmerssen, Vedel, van den Brink, \& Schoevers, 2015). 
Patients with both substance and mental disorders have more persistent and severe symptoms (Brady, Rierdan, Peck, Losardo, \& Meschede, 2003; Margolese, Malchy, Negrete, Tempier, \& Gill, 2004). They have a less positive prognosis and worse outcome than patients with only one disorder (Quimette, Gima, Moos, \& Finney, 1999; Petry, 2000; Morisano, Babor, \& Robaina, 2014) and there is a high risk of suicide especially for patients with a bipolar disorder (Dalton, Cate-Carter, Mundo, Parikh, \& Kennedy, 2003; Kelly, Cornelius, \& Lynch, 2002).

The prevalence of multiple mental disorders combined with SUD is high, but little is known about these more complex patterns in treatment populations (Urbanoski, Kenaszchuk, Veldhizen, \& Rush, 2015).

\section{Biopsychosocial perspectives on addiction}

Addiction, or substance use disorder, is a complex and multifactorial problem within an interdisciplinary knowledge area that spans biology, psychology and sociology, often referred to as a biopsychosocial perspective. SUD theories in the different disciplines are often interconnected. Some of these theories and explanations will be commented on here. A frequently used concept in this area is vulnerability or risk factors.

There is a complex relationship between personality and the development of addiction or SUD. There are various theories about personality, and the dominating theory in this field is the trait theory, which is a biopsychosocial theory about temperament and characteristics.

The personality consists of a variety of basic traits along a continuum. The basic traits have a biological foundation, where genetics, brain functions and physiological activities are central processes, which regulate, affect and transmit how these traits are expressed. These basic traits can be moderated by psychosocial factors and they reach stability and continuity in adulthood. The most commonly used model for personality is the Big Five, or the fivefactor model (Digman, 1990), which is based on the idea that the personality is composed of five originally biological traits: openness, conscientiousness, extraversion, agreeableness and neuroticism (Berglund \& Fahlke, 2011).

There are some personality traits which increase the risk of developing addiction and there are traits which are reinforced by the substance abuse. In the five-factor model there are two traits associated to SUD, extraversion and neuroticism (sometimes called emotional instability).

Extraversion involves energetic, impulsive, talkative, assertive, sociable, sensationseeking behavior, where impulsivity and sensation seeking are related to SUD. Low activity of monoamine oxidase (MAO, a family of enzymes) in combination with childhood adversity seems to increase the risk of impulsivity and sensation-seeking behavior. Sensation seeking may also be related to a special variety of the gene for a dopamine receptor (DRD4). Possibly the dopamine system is inactivated, which increases the risk of risk-taking activities including using alcohol and drugs (Berglund \& Fahlke, 2011). The part of the brain affected by alcohol and drugs is the reward system and there are theories which indicate that certain individuals need an increased activation of this system to experience pleasure and euphoria. 
Neuroticism means behavioral and emotional expressions such as anxiety, anger, depression, and deficit in self-esteem. Less capability to handle stressors may lead to substance use as a way of handling those and thus constitute a risk factor for developing SUD (Berglund, 2009). Individuals with a long period of alcohol use (more than 10 years) have a higher level of emotional instability. It has been shown that long-term alcohol use has a negative effect on levels of serotonin, an important neurotransmitter for mood regulation, increasing the vulnerability to anxiety and depression (Berglund, Fahlke, Berggren, Eriksson, $\&$ Balldin, 2006).

Biomedical research has contributed to increased knowledge of the brain's reward system. The basic hypothesis is that the substances take over the reward system, affecting the neurotransmission dopamine system (Heilig, 2011). Still this does not explain the craving developed over time. For this there are two theories, sensitization and negative reinforcement. The sensitization theory describes a change in the reward system, from feelings of euphoria to longing for the substance itself. According to the negative reinforcement theory, the reward system becomes overloaded, reacting to reduce the positive feelings. Here the neurobiological mechanisms come close to the psychological learning theory of positive and negative reinforcements. Both the sensitization and the negative reinforcement explanation models state permanent modifications of the brain, implying a chronic brain disease (Volkow, Koob $\&$ McLellan, 2016). Heilig (2015) names it a chronic relapsing brain disease.

Genetic vulnerability is especially important for alcohol use disorder (AUD), as shown in twin and adoption studies (Bohman, Cloninger, Sigvardsson, \& von Knorring, 1987; McGue, 1999; Cloninger, Sigvardsson, \& Bohman, 1996). The genetic hereditary component for developing AUD is estimated at about 50-60 \% of the risk. There is a great variability, which means that genetic vulnerability can be low in one person, but high in another. Biological factors of importance for AUD are factors connected to the metabolism and the effects of the blood concentration of alcohol.

Cloninger and colleagues (1996) found two types of alcohol use disorder. Type I is characterized by later and sporadic onset among individuals with good social adaptation, corresponding to $75 \%$ of persons with AUD. Type II is characterized by an early onset, more severe symptoms of alcohol dependency and psychopathology, and a father with severe AUD. In type II, criminality and poly-substance use are more common, with traits of antisocial personality disorders, representing $25 \%$ of the individuals with AUD. Although genetics contribute as a risk factor, it is important to stress that the majority with this vulnerability do not develop AUD. This typology has recently been discussed by Wennberg, Berglund, Berggren, Balldin and Fahlke (2014), finding it less appropriate for AUD individuals living under more socially stable conditions in a Swedish city.

There are individual vulnerabilities which have an impact on psychological development and maturity. These vulnerabilities can be biological, psychological and social in different combinations, which are described in the classic stress-vulnerability theory by Zubin and Spring (1977), originally for explaining the development of schizophrenia. The basic principle is that the more an individual is exposed to negative stressors and the more vulnerabilities she 
or he has, the greater the risk of developing mental health problems and SUD. Examples of risk factors are neglect, physical and sexual abuse during childhood and difficulties at school.

Within the psychological framework there are various explanations for SUD, e.g. the attachment theory and the self-medication hypothesis (SMH). Within the attachment theory, an insecure attachment style or pattern is considered to be a risk factor for developing substance use problems. More aspects on the relationship between attachment and SUD are discussed below (Attachment and SUD section). The self-medication hypothesis was introduced by Khantzian (1985) and claims that alcohol and illicit drug use are used to regulate emotions such as anxiety, aggression, pain, loneliness, and experiences of trauma. The choice of drug corresponds to regulating specific emotions. The well documented cooccurrence of SUD and psychological distress has given some support to this hypothesis. However, it has also been seriously criticized, e.g., for neglecting the effect of the substance per se (Lembke, 2012; Heilig, 2015).

\section{Treatments for SUD}

Treatments for SUD include pharmacological and psychosocial interventions, alone or in combinations. The national guidelines for SUD treatment (Socialstyrelsen, 2017) give recommendations on a priority scale from 1 to 10 , where 1 is the most recommended. The guidelines compare different kinds of interventions and recommend which one(s) should be implemented, taking into account the severity of the condition, the benefit for the patient, the cost of the intervention in relation to its effect and if there are other, better interventions for this specific intervention. The studies behind the recommendations are based on the ICD-10 and DSM-IV diagnosis systems.

The Swedish guidelines are closely in line with the guidelines and recommendations in the USA, expressed through the National Institute of Drug Abuse (NIDA), the National Institute of Alcohol Abuse and Alcoholism (NIAAA) and the Substance Abuse and Mental Health Services Administration (SAMSHA), and also with the World Health Organization (WHO) recommendations. The following sections give a brief overview of SUD treatments in Sweden.

\section{Medical treatments}

For alcohol dependence, three treatments are given priority 1 according to the Swedish guidelines (Socialstyrelsen, 2017): disulfiram (Antabuse), naltrexone, and acamprosate. Disulfiram is an aversion treatment to establish sobriety. Naltrexone decreases the rewarding effects of alcohol, while the main effect of acamprosate is to reduce craving and the risk of relapse (Heilig, 2011). There is an under-prescription of these medications in Sweden although it is possible for all doctors to prescribe them (Socialstyrelsen, 2017).

For opioid dependence, priority 1 is given to buprenorphine together with naloxone (Suboxone). Methadone is given priority 2. Both buprenorphine and methadone are opioids with a long-acting effect, and they are used in maintenance treatments. 


\section{Psychological and psychosocial treatments}

Table 1 gives an overview of some of the recommended treatments for adults according to the Swedish guidelines (Socialstyrelsen, 2017). The methods used in the present research project are indicated.

Table 1. Some of the recommended psychological and psychosocial treatments for adults according to the Swedish guidelines (Socialstyrelsen, 2017), including those used in this study.

\begin{tabular}{|c|c|c|c|}
\hline Substance & Method & Priority & Used in this study \\
\hline \multirow[t]{6}{*}{ Alcohol } & MET $^{1}$ & 1 & \\
\hline & $\mathrm{TSF}^{2}$ & 2 & \\
\hline & $\mathrm{CRA}^{3}$ & 2 & $\mathrm{X}$ \\
\hline & $\mathrm{CBT}^{4} / \mathrm{RP}^{5}$ & 2 & $\mathrm{X}$ \\
\hline & SBNT $^{6}$ & 2 & \\
\hline & $\mathrm{PDT}^{7} / \mathrm{ITP}^{8}$ & 4 & $\mathrm{X}$ \\
\hline \multirow[t]{2}{*}{ Cannabis } & $\mathrm{CBT}^{4} / \mathrm{RP}^{5}$ & 3 & $\mathrm{X}$ \\
\hline & $\mathrm{RP}^{5}+\mathrm{MI}^{9} / \mathrm{MET}^{1}$ & 3 & $\mathrm{X}$ \\
\hline \multirow{4}{*}{$\begin{array}{l}\text { Amphetamine/ } \\
\text { cocaine }\end{array}$} & $\mathrm{TSF}^{2}$ & 3 & \\
\hline & $\mathrm{CRA}^{3}+\mathrm{CoM}^{10}$ & 3 & \\
\hline & MATRIX $^{11}$ & 3 & \\
\hline & $\mathrm{CBT}^{4} / \mathrm{RP}^{5}$ & 4 & $\mathrm{X}$ \\
\hline \multirow[t]{3}{*}{ Opioid $^{*}$} & $\mathrm{CBT}^{4} / \mathrm{RP}^{5}$ & 3 & $\mathrm{X}$ \\
\hline & $\mathrm{CRA}^{3}$ & 4 & $\mathrm{X}$ \\
\hline & $\mathrm{PDT}^{7}$ & 5 & $\mathrm{X}$ \\
\hline \multirow[t]{2}{*}{ Alcohol/illicit drugs ${ }^{* *}$} & $\mathrm{IBCT}^{12}$ & 3 & \\
\hline & $\mathrm{NT}^{13}$ & 4 & \\
\hline
\end{tabular}

${ }^{*}$ within the framework for maintenance treatment

*** given in addition to other treatment(s)

${ }^{1}$ Motivational Enhancement Therapy , ${ }^{2}$ Twelve Step Facilitation, ${ }^{3}$ Community Reinforcement Approach,

${ }^{4}$ Cognitive Behavioral Therapy, ${ }^{5}$ Relapse Prevention, ${ }^{6}$ Social Behavior and Network Therapy, ${ }^{7}$ Psychodynamic Therapy,

${ }^{8}$ Interactional Therapy, ${ }^{9}$ Motivational Interviewing, ${ }^{10}$ Contingency Management, ${ }^{11}$ Intensive Outpatient Alcohol \& Drug

Treatment Program, ${ }^{12}$ Integrative Behavioral Couple Therapy, ${ }^{13}$ Network Therapy

The MATRIX program combines TSF and RP with social network support and regular urine analyses. For alcohol use disorders, PDT and ITP are considered to yield the same effect as CBT and RP; however, they have less evidence-based support (Socialstyrelsen, 2017).

For SUD patients with co-occurring disorders, the Swedish guidelines consider it important to treat both disorders at the same time, recommending an integrated treatment. Although comorbidity is very frequent among SUD patients and there is a large demand for guidelines, the evidence-based support is limited and with a strong heterogeneity e.g. in terms of patient groups and treatments used (Socialstyrelsen, 2017).

The treatments provided at the three outpatient SUD centers included in this study were Motivational Interviewing (MI), Relapse Prevention (RP), Community Reinforcement Approach (CRA), Cognitive-Behavioral Therapy (CBT), Psychodynamic Therapy (PDT), psycho-educative interventions, crisis intervention, supportive therapy and counselling, alone or in different combinations.

MI is a specific counselling method to strengthen the patient's motivation for behavior change, based on four principles. The first is that the therapist shows empathy by reflective 
listening, accepting the patient's perspective. The second principle is to explore and develop the patient's discrepancies between positive and negative effects of substance abuse. The third is to accept the patient's resistance to change by "rolling with the resistance", i.e. using reflective listening. The fourth principle is to strengthen the patient's self-efficacy, focusing her or his resources and belief that change is possible. MI was developed by Miller (1983) and Miller and Rollnick (1991). The MI method can be given as a short series of sessions, commonly one to four, and can be combined with other interventions.

RP (Marlatt \& Donovan, 2005) is a cognitive behavior method based on the assumption that substance use is a way of coping with stress and that relapse is triggered by social pressure and by frustrated situations. This manual-based treatment provides the person with coping skills to prevent relapse into substance abuse. RP includes the identification and prevention of high-risk situations for relapse, strategies for coping with craving, selfmonitoring of craving, training in social skills and problem-solving. RP is normally applied over the course of eight weeks, in group format or - as was the case in this study individually.

CRA (Hunt \& Azrin, 1973; Meyers \& Miller, 2001) is a manual-based intensive behavioral treatment that encourages a change of lifestyle by involvement in alternatives that are more rewarding than substance abuse. The therapist and the patient investigate together the circumstances that trigger substance abuse and describe the resulting consequences. They carry out the same analysis for situations where the patient is free of substance abuse. The emphasis is on social activities, by mobilizing the patient's personal network and supporting her or him to work or study. Important strategies are training in self-control, problem-solving, communication, and learning to say no to alcohol/drugs. MI, RP and medical treatment for substance abuse can be included. A CRA treatment is given in about 12 sessions over a threemonth period, sometimes with follow-up booster sessions.

CBT (Carroll, 1998; Gyllenhammar, 2012) has been developed as a combination of the basic principles of cognitive and behavioral psychology. Cognitive theory deals with thinking and how it affects our feelings and behaviors. Behavioral theory deals with how we learn to act and interact with our surrounding environment. The CBT strategies aim towards the therapist and the patient jointly analyzing the circumstances and situations which positively and negatively reinforce substance abuse. The goal is to find sober alternatives to the positive reinforcements of the substance abuse and to develop new strategies to deal with these problems. CBT treatment is characterized by an active and structured way of working, where the goals are clearly defined and measurable. A treatment plan is established, which is evaluated during the treatment course. The patient is given homework from session to session. Usually there is one session per week for about five to 20 weeks.

PDT (Frederickson, 1999; Abbass et al., 2014) has its basis in psychoanalytical theory and humanistic psychology. A core concept is that man has an unconscious inner life principally formed from close relationships during childhood, and that these attachment patterns and experiences continue to affect future relationships and life choices. Unconscious defenses against disturbing and unpleasant feelings, fears and inner conflicts lead to mental 
symptoms and limitations. Other important concepts are the interpretation of transference and counter-transference, and insight. Relational psychotherapy is a recent orientation of PDT, which has the goal of better understanding how the patient relates to others and how her or his relating patterns impact on mental and emotional well-being. In PDT the therapist is engaged and curious, with a desire to understand the patient's problems and situation. The collaboration is more based on a joint investigation, without advices from the therapist. PDT for SUD patients aims at an increased consciousness and elaboration of emotional conflicts which can constitute background factors to substance abuse. PDT can be offered as a short treatment of eight to 15 sessions, or as a long-term therapy over the course of a year or more.

In Studies II and III, SUD treatments were grouped in three orientations, defined as:

- Directive - including RP, CRA and CBT

- Reflective - including PDT and relational psychotherapy

- Supportive - including psycho-educative interventions, crisis intervention, supportive therapy and counselling

MI was used in addition to other treatments but was not used for the classification. For a minority of the patients, it was not possible to classify their treatment into a specific orientation and they were labelled "not clearly defined".

\section{Attachment}

\section{Background to attachment}

Attachment theory has its roots in Bowlby's (1958; 1960a; 1960b) seminal work and is based on concepts from ethology and developmental psychology. Attachment is considered to be an inborn system that motivates the child to seek proximity to a familiar caregiver under condition of threat - a safe haven - and who also serves as a secure base for a child while exploring the world (Ainsworth, 1989; Bowlby, 1969). The repeated interactions between the child and the caregiver are encoded in the implicit memory system and form internal working models of the self and of others (IWMs). The IWMs form a basis for the child's capacity to maintain close relationships, regulate emotions and cope with stress and negative experiences in the future (Main, 1995; Wallin, 2007). Attachment in adulthood can be understood as one's mental representations of self and others.

Although attachment patterns developed in childhood are generally considered to be consistent throughout life, there is a discussion on continuity and discontinuity in adult attachment. A review of more than 30 published studies shows moderate to high stability of attachment patterns over both shorter (weeks) and longer (years) periods (Miculincer \& Shaver, 2016). However, crucial emotional experiences taking place, e.g., the loss of a parent, finding a supportive partner, divorce, or the death of a romantic partner, may change these patterns (Bakersman-Kranenburg \& van IJzendoorn, 2009; Waters, Merrick, Treboux, Crowell, \& Albersheim, 2000).

A consistent finding is that individual psychological vulnerabilities constitute a predictor of more dramatic changes in attachment patterns over time (Allen, McElhaney, Kuperminc, \& 
Jodl, 2004; Davila \& Cobb, 2003). Cozzarelli, Karafa, Collins, and Tagler (2003) studied women who had undergone abortions and found a relatively low level of stability over two years. They argue that the changes from insecure to secure were related both to individual vulnerabilities and to alterations of the perceptions of self and others, while the opposite changes from secure to insecure were more specifically related to vulnerability issues.

There is also some evidence for age-related variations in attachment patterns, e.g. that the anxious dimension moves towards security for middle-aged people who have obtained more social security after marriage and becoming parents (Chopic, Edelstein, \& Fraley, 2013).

Attachment studies originally focused on children. Ainsworth, a former colleague of Bowlby, developed a research tool called the Strange Situation (Ainsworth, Blehar, Waters, \& Wall, 1978). In an experimental situation she studied the reaction of a child between the ages of twelve and eighteen months, when separated from her or his caregiver. Ainsworth was able to distinguish three different attachment patterns: a secure pattern, an anxious-avoidant pattern and an anxious-ambivalent pattern. Later, she found that there was a group of children who did not fit into the three patterns and added a fourth category: disorganized (Main \& Solomon, 1986).

Among adults the most commonly applied method for classifying attachment patterns is the Adult Attachment Interview (AAI; George, Kaplan, \& Main, 1984, 1985, 1996). This is a semi-structured interview focusing on the person's early relationships with her or his parents, which also tries to get access to unconscious perceptions. Transcripts from AAIs are coded as one of three main patterns: secure-autonomous, insecure-dismissive or insecure-preoccupied. Interviews which cannot be categorized are coded as "cannot classify". A person may additionally be classified as unresolved to trauma/loss. By using the AAI it is also possible to evaluate a person's reflective functioning (RF; Fonagy, Gergely, Jurist, \& Target, 2002). AAI has been evaluated in many studies and is considered to have the best scientific support in this field, but it is quite a complicated and time-consuming way to evaluate attachment patterns.

Another way of measuring adult attachment is through self-report questionnaires. This approach has its origin in social psychology, and its focus is on current relationships with partners, family members, and close friends. It takes into account conscious mental representations, thoughts and feelings. The first self-report questionnaire was created by Hazan and Shaver (1987). They translated and adapted Ainsworth's descriptions of patterns of childhood attachment behavior into adult attachment in three categories named as secureautonomous, insecure-dismissive and insecure-preoccupied.

Bartholomew (1990) and Bartholomew and Horowitz (1991) revised the three category classifications and proposed a two-dimensional model with anxiety and avoidance as dimensions, yielding four attachment types with fearful as a new category (see Appendix 3). Brennan, Clark and Shaver (1998) developed an attachment measure using factor analyses of the existing adult attachment measures, with the objective of replacing them with a new form - the Experiences in Close Relationships (ECR) scale. The factor analysis showed that most of the variance in adult attachment was accounted for by the two dimensions anxiety and avoidance. ECR is the most frequently used self-report attachment form and has been used in 
a variety of patient groups (Levy, Ellison, Scott, \& Bernecker, 2011; Marmarosh et al., 2009). The two constructs for measuring adult attachment, interview-based and self-rated, are weakly associated which makes comparisons between different studies complicated. They actually measure different phenomena (Roisman et al., 2007; Shaver, Belsky, \& Brennan, 2000).

There are many studies which indicate that insecure attachment is related to difficulties in emotion regulation (Mikulincer, Shaver, \& Berant, 2013). Instead of seeking proximity to an attachment figure, an insecure individual uses other strategies to regulate emotions - either by deactivating or hyperactivating the attachment system, to handle threats, frustrations and rejections.

Finally, Mickelson, Kessler and Shaver (1997) found in a non-clinical adult population $(\mathrm{n}=7716)$ that $59 \%$ rated themselves as securely attached, $11 \%$ had an anxious attachment style and $25 \%$ had an avoidant attachment style. Other studies on non-clinical populations show similar distributions.

\section{Attachment and psychotherapy}

A patient's attachment pattern or attachment style may have significance for the therapeutic process and for the outcome of the psychological treatment. It may also be seen as a moderating or mediating variable, and as a meaningful outcome in itself, as a complement to symptom change (Daniel, 2006). A review of three meta-analyses of fourteen outcome studies $(n=1467)$ reported better treatment outcomes for patients with secure attachment, while high anxious attachment predicted worse outcomes in psychotherapy (Levy et al., 2011). In general, patients with a secure attachment have a better outcome in psychotherapy (i. e. Meyer, Pilkonis, Proietti, Heape, \& Egan, 2001) and are more compliant than insecure patients (Dozier, 1990), but the results are rather inconsistent. On the other hand, patients with a dismissing attachment pattern (Fonagy et al., 1996) showed greater improvement compared to secure and preoccupied patients.

In the meta-analysis of Levy et al. (2011), the mean weighted $r$ between attachment security and psychotherapy outcome was .182 (Cohen's weighted $\mathrm{d}=.370$ ). For attachment anxiety and psychotherapy the outcome was -.224 (Cohen's weighted $\mathrm{d}=-.460$ ), i.e. higher anxiety led to worse outcome. Attachment avoidance was not correlated to outcome.

There are a few studies where the patient's attachment style is measured in relation to the therapist (Mallincrodt, Gantt, \& Coble, 1995) and where the therapists' attachment style is also measured and taken into consideration as well as their experience of psychotherapy (Dozier, Cue, \& Barnett, 1994; Slade, 2016). Bowlby also pointed out (1988) that the therapist may become an attachment figure and the patient may perceive the relationship as a corrective emotional experience (Alexander \& French, 1946; Mallincrodt, 2010). It is a dynamic system that offers the possibility of change through psychotherapy.

Until recently the research on attachment and psychotherapy has mainly considered the outcomes of pre- and post-measures and usually on a group level. There are few studies of the process in the treatment (Slade, 2016) with some important exceptions. Daniel (2011) and 
Talia and colleagues (2014) study the in-session processes on a "microlevel" in different ways.

\section{Attachment and SUD}

There is evidence that SUD patients more often have an insecure attachment style compared to individuals in non-clinical populations (Mikulincer \& Shaver, 2016; Schindler \& Bröning, 2015). Insecure attachment may be one factor that contributes to SUD, as attachment is related to emotion regulation, relationship behavior and coping skills (Padykula \& Conklin, 2010). On the other hand, changes in observed and self-reported attachment may also be a consequence of substance abuse.

Schindler and Bröning (2015) reviewed research on the relationship between attachment and substance use disorder (SUD) in adolescence. They looked for evidence of a possible general link between SUD and insecure attachment and for links between specific forms of SUD and specific patterns of attachment, and found that empirical evidence strongly supports the assumption of insecure attachment in SUD samples. With regard to specific attachment patterns, the review mainly points towards fearful and dismissing attachment.

We do not know whether there is a general relationship between insecure attachment and SUD or whether specific attachment styles are related to specific forms of SUD (Mikulincer \& Shaver, 2016; Schindler, Thomasius, Petersen, \& Sack, 2009). Published results indicate different patterns of attachment in different SUD groups; some studies found fearful attachment among heroin abusers/addicts and more heterogeneous results in abusers of other substances (e.g., Schindler et al., 2005). Although most studies suppose that the relationship is general, some recent studies have suggested that externalizing behavior, potentially associated with avoidant attachment, might also lead to more risk-taking behavior with regard to substance use (Zucker, Heitzeg, \& Nigg, 2011), whereas internalizing behavior associated with anxious attachment may lead to substance use as a way of regulating negative emotions (Hussong, Jones, Stein, Baucom, \& Boeding, 2011).

A study of Hiebler-Ragger, Unterrainer, Rinner and Kapfhammer (2016) on SUD inpatients with a borderline personality organization found that the drug of choice could not be regarded as an indicator of the extent of attachment deficits or personality pathology. They could not find any difference between alcohol and polysubstance use disorders, with all patients showing significant deficits in attachment parameters in comparison to a control group.

Attachment processes are seen as one influence among others within a multifactorial model of adolescence substance use. Their importance for understanding SUD lies in the focus on emotion regulation, relationship behavior, and coping strategies. Studies seem to confirm the assumption that secure attachment is a protective factor against and insecure attachment a risk factor for SUD (Schindler \& Bröning, 2015).

Individuals with SUD have often been victims of sexual, physical, or emotional maltreatment (Kendler et al., 2000; Riggs \& Jacobvitz, 2002). Fletcher, Nutton, and Brend (2015) believe that traumatic early childhood experiences and insecure attachment are both 
independent and interrelated risk factors for SUD. As such experiences are often associated with disorganized attachment, we might expect higher rates of disorganized or fearful attachment among these individuals.

Methodological problems such as poor assessment of SUD and the use of different measures of attachment limit comparability. The role of attachment in developing SUD problems is understudied. We know that insecure attachment is a risk factor for a host of mental health problems among adolescents. However, we still lack an overview of existing research that links insecure attachment with SUD.

\section{Alliance}

\section{Background to alliance}

The concept of alliance has its roots in the psychodynamic tradition. Freud never used the concept, but described how patients collaborated and remained in treatment even though they had to deal with increased anxiety (Freud, 1912/1958; 1913). The concept was later elaborated on by Sterba (1934), Zetzel (1956) and Greenson (1965). Zetzel introduced the term therapeutic alliance and Greenson later introduced the term working alliance. Rogers' empirical work on conditions that facilitate the therapeutic process, with the therapist showing empathy, genuineness, trustworthiness and warmth, etc., has been an important contribution (Rogers, Gendlin, Kiesler, \& Truax, 1967). The concept of alliance has been developed and now refers to how the relationship between the patient and the therapist serves to assist the progress of the therapeutic process, independent of treatment orientation (e.g., Luborsky, 1976).

Bordin $(1975,1989,1994)$ introduced a pan-theoretical concept of working alliance consisting of three aspects: agreement on goals of the therapy; agreement on tasks to achieve these goals; and the development of a bond of trust, respect and confidence between the patient and the therapist to reach these goals. In psychoanalytic theory, both conscious and unconscious aspects of the alliance have been considered; in empirical research the emphasis of alliance is on conscious aspects of the relationship and the collaboration between the patient and the therapist.

There are multiple perspectives on the concept of "alliance". Researchers and clinicians have interpreted the concept according to their view of the therapeutic process. For example Safran and Muran (2000) have argued that the dyadic relationship behind the formation and maintenance of the alliance is the core of the therapeutic work, considering alliance as a process of intersubjective negotiation. Others look upon the alliance as a byproduct of an effective treatment, or as a common factor (Horvath, Del Re, Flückiger, \& Symonds, 2011).

There are more than 70 different instruments for measuring alliance. Four are considered to be core measures: the California Psychotherapy Alliance Scale (CALPAS), the Helping Alliance Questionnaire (HAq), the Vanderbilt Psychotherapy Process Scale (VPPS), and the Working Alliance Inventory (WAI). The WAI is the most frequently used measure in alliance research (Martin, Garske, \& Davis, 2000). 


\section{Alliance and psychotherapy}

The association between alliance and outcome in psychological treatment is well established. Studies have shown a moderate but consistent relationship between alliance and treatment outcome, independent of the orientations of therapies, therapists, patient groups, raters, culture, measurement methods and research designs (Horvath et al., 2011). The patient's attachment orientation has been shown to have an influence on alliance (Eames \& Roth, 2000; Diener \& Monroe, 2011). The meta-analysis by Horvath et al. (2011) found the association between patient-rated alliance and outcome to be $r=.28$ and the association between therapist-rated alliance and outcome to be $r=.20$. Baldwin and Imel (2013) and Del Re, Flückiger, Horvath, Symonds and Wampold (2012) have emphasized the importance of the therapist contribution to the alliance-outcome correlation.

A recent meta-analysis based on 295 independent studies with more than 30000 patient ratings of the alliance found a correlation between alliance and outcome in face-to-face psychotherapy of $r=.278$. Internet-based psychotherapy showed a similar correlation of $r=$ .275 (Flückiger, Del Re, Wampold, \& Horvath, 2018).

Criticism has been directed towards the current research methods for studying alliance and outcome, arguing that they are not sufficiently sophisticated to allow for an understanding of the complex interactions in the therapeutic process (e.g. Lorenzo-Luaces \& DeRubeis, 2018). However, innovative research in this field is ongoing, e.g. on within-person change and how to identify and isolate patient characteristics of importance for alliance development and outcome (e.g. Hoffmann \& Barlow, 2014; Zilcha-Mano, 2017).

There is also an on-going discussion about causality with regard to alliance and outcome. Critics of the idea that alliance has a causal influence on symptom change have argued that symptom change may cause alliance improvement (DeRubeis \& Feeley, 1990; Barber, 2009). Studies with repeated measures of alliance and symptoms during treatment in general indicate that there may be an influence in both directions (Tasca \& Lampard, 2012; Crits-Christoph, Gibbons, Hamilton, Ring-Kurtz, \& Gallop, 2011; Xu \& Tracey, 2015) although the influence of alliance on symptom change may be greater (Falkenström, Granström, \& Holmqvist, 2013; Zilcha-Mano, Dinger, McCarthy, \& Barber, 2014).

In a meta-analysis of Tryon, Blackwell and Hammel (2007), based on 32 studies, the correlation reported between patient- and therapist-rated alliance during individual psychological treatment was $r=.36$. They also showed that patients rated the alliance higher than the therapists did.

\section{Alliance and SUD}

Empirical studies of predictors of the alliance in SUD treatment show varying results. Several studies have found that the type of substance use does not predict the quality of the early alliance, and nor does the type of psychological symptoms or the severity of the symptoms (Luborsky et al., 1996; Belding, Iguchi, Morral, \& McLellan, 1997; Barber et al., 1999; De Weert-Van Oene, De Jong, Jörg, \& Schrijvers, 1999; Connors et al., 2000). Modest but consistent relationships were found between the alliance and motivation, treatment readiness, and positive previous treatment experiences (Meier, Barrowclough, \& Donmall, 
2005a). Patients who had better motivation and coping strategies, and also a secure attachment style, were more likely to develop good alliances (Meier, Donmall, Barrowclough, McElduff, \& Heller, 2005b). Significantly higher therapist-rated alliance was reported for patients with a higher education level (Belding et al., 1997).

External pressures and environmental factors such as social support seem to have a fairly strong influence on the alliance (Meier et al., 2005b; Connors, Carroll, DiClemente, Longabaugh, \& Donovan, 1997; Joe, Simpson, \& Broome, 1998; Garner, Godley, \& Funk, 2008). Barrowclough, Meier, Beardmore, and Emsley (2010) suggest that the alliance is associated with the patient's psychological and social resources, treatment-related attitudes and earlier treatment experiences. In a study of young adults, older age, higher baseline level of motivation, self-efficacy, coping skills, and commitment to Alcoholics Anonymous/ Narcotics Anonymous (AA/NA) predicted a stronger alliance (Urbanoski, Kelly, Hoeppner, \& Slaymaker, 2012). A study among adolescents showed that those with more severe SUD developed a better alliance (Bertrand et al., 2013). Bertrand and colleagues (2013) hypothesized that the therapists became more involved with adolescents whose SUDs were more severe. Allen and Olson (2016) found that the treatment of patients with more severe SUD led to more attrition and thus a need for more support, concluding that alliance, motivation and retention are intertwined.

Studies have found that treatment motivation and parental support have significant impacts on SUD treatment engagement and outcome (Bender et al., 2006; Winters, Botzet, \& Fahnhorst, 2011). Zuroff and colleagues (2007) found that motivation was a better predictor of outcome in comparison with the therapeutic alliance.

Greenfield and colleagues (2007) found that women with SUDs are less likely to enter treatment compared with their male counterparts. Gender was not, however, a significant predictor of treatment retention, completion or outcome.

A study of group counselling by Crits-Christoph, Johnson, Connolly Gibbons, and Gallop (2013) showed that the alliance with the counsellor was positively associated with outcome, but not with the patient's self-disclosure and participation.

There is no gold standard for measuring the outcomes of SUD patients in psychological treatment (Dutra et al., 2008). Common outcome measures are reduction in substance use, abstinence, abstinence duration, changes in psychological distress and retention in treatment. Findings regarding the association between patient-rated alliance and different outcomes in the treatment of SUD patients have been mixed. Flückiger et al. (2013) found a correlation of $\mathrm{r}=.175$ between patient-rated alliance and outcome in SUD patients. In mixed samples, containing both SUD patients and patients without substance abuse, a 10\% increase of SUD patients (other than alcohol) in the samples decreased the alliance-outcome relationship by .01 (Flückiger et al., 2013). In the most recent meta-analysis, the correlation between alliance and outcome for SUD patients, based on 29 studies, was $r=.14$ (Flückiger et al., 2018), implying a significantly lower association than for other patients $(\mathrm{Q}(8)=27.958 ; \mathrm{p}<.001)$. 
Thus, there seem to be indications of weaker associations between alliance and outcome in SUD treatments compared to other patient groups (Horvath et al., 2011; Barber et al., 1999). A reason could be that the use of substances may damage neuro-biological systems that are required for optimal relational capacity and mentalization, thus hindering the patient's constructive use of the alliance (Bates, Bowden, \& Barry, 2002). Flückiger et al. (2013) also stress the importance of socioeconomic status, minority status and specific drugs and their interaction as potential moderators of the alliance-outcome association in treatments for SUD patients. Flückiger et al. (2018) argued that SUD "clients in these treatments are often volatile and have multiple problems".

In summary, the results of studies of the association between alliance and outcome in SUD treatments indicate that the relationships may be more complex than for other patients.

\section{Summary of present knowledge and research questions to address}

SUD outpatients in routine care constitute a heterogeneous group with different types of substance abuse and high rates of comorbidity. Moreover, they are rarely the focus of treatment outcome evaluations. An important objective for this thesis has been to describe more in detail this heterogeneity and how it affects the outcome as measured by posttreatment substance use and levels of psychological distress. The outcome of the different treatment orientations is another important aspect to assess, and there is a lack of Swedish studies in this area.

We also see a need for more research on how SUD patients differ from other patient groups in terms of how attachment pattern and patient-therapist alliance affect outcome. Earlier studies have indicated that SUD patients more often have an insecure attachment style, compared to a non-clinical population. There are also results indicating a lower association between patient-therapist alliance and outcome for SUD patients, compared to other patient groups. 


\section{Aims}

The aims of the present thesis were to evaluate the effects of community-based psychological treatment on SUD patients' psychological distress and substance use, and also to analyze the importance of their attachment style and the alliance with regard to treatment outcome.

\section{Paper I}

The aim of Paper I was to evaluate the effects of community-based psychological treatment on SUD patients' psychological distress and substance use.

\section{Paper II}

The aim of Paper II was to explore the associations between self-rated attachment style, psychological distress, substance use, and outcome among SUD outpatients in psychological treatment.

\section{Paper III}

The aim of Paper III was to assess the relationship between alliance and treatment outcome of SUD patients in routine care and to study the influence of type of substance use, attachment style, and treatment orientation as potential moderators on this relationship.

\section{Methods}

The three studies are based on data from the same research project. The method section is therefore unified and covers all three studies.

\section{Participants}

The patients were recruited from May 2011 to March 2014 from one outpatient unit for dependency disorders within a county council and two outpatient centers for SUD treatment within the social services of two municipalities in Sweden. All patients who were referred or self-referred for psychological treatment to a social worker or a psychotherapist were asked to participate in the study. Data collection ended in March 2016. As illustrated in the flowchart in Figure 1, a total of 172 patients were considered for inclusion in the study, of which 119 patients ultimately agreed to participate and 53 declined. The reasons for not participating were that the patients found the procedure too complicated or they did not want to participate in any kind of study. In some cases, the therapists regarded the patient as not being able to participate because of serious mental illness, poor physical condition or language problems. Among the 53 patients declining or considered unable to participate, therapist evaluation data were reported for 46 patients. These patients did not differ in terms of gender, age and substance use from the participating patients. 


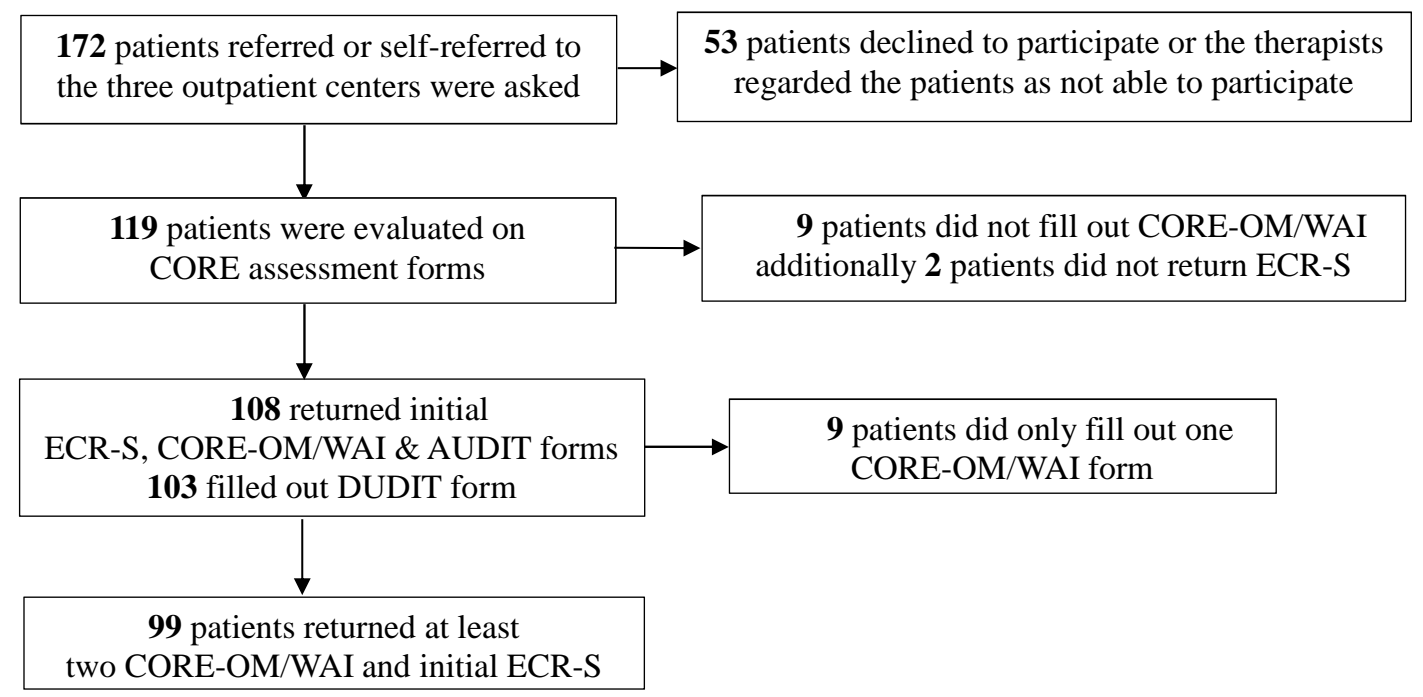

Figure 1. Flowchart valid for Paper II and III. For Paper I, which did not include ECR-S forms, $n=100$.

Descriptive data for the 119 patients were collected via the CORE Therapy Assessment form. Among the 119 patients, 112 (94\%) were born in Sweden and 93 (78\%) were men, with somewhat fewer women than expected (25-35\%). The mean age was 34.9 years (range 16 to 69): 33.5 years for men and 40.0 years for women. At treatment start $45 \%$ of the participants were employed, $18 \%$ were studying, and $37 \%$ had no current occupation, i.e. they were unemployed, on sick leave or retired. The highest educational background was a university degree (3\%), followed by upper secondary diploma (45\%) and compulsory school graduation (30\%), with the remaining $22 \%$ having incomplete compulsory school education. Forty-four percent of the participants were living alone. Six percent were caring for children under 5 years of age and $11 \%$ for children older than 5 years.

Of the 119 patients, 74 had an ICD-10 diagnosis and of these 67 had an SUD diagnosis. The most frequent SUD diagnoses were alcohol dependence $(n=29)$, alcohol withdrawal $(n=11)$, opioid dependence $(n=11)$, alcohol abuse $(n=8)$ and other psychoactive substance dependence $(n=3)$. The patients treated at the county council outpatient unit for dependency disorders were given medical diagnoses whereas the patients at the municipal social services SUD outpatient centers were not.

Of the 109 patients filling out AUDIT at treatment start, 85 were above the cut-off and distributed as $33 \%$ having moderate, $6 \%$ large and $61 \%$ very large problems (see AUDIT classification below in the Instruments section). Of the 105 patients filling out DUDIT at treatment start, 51 scored above the cut-off with $49 \%$ classified as having drug-related problems and $51 \%$ showing dependence (see DUDIT classification below in the Instruments section).

There were some significant differences between the patients attending the municipal SUD treatment centers and those attended by the county council outpatient unit for 
dependency disorders. The patients at the municipal SUD centers were younger (mean age = median age $=21.0$ years, range $16-46$ years) than those attending the county council unit for dependency disorders (mean age $=44.0$ years, median age $=45.5$ years, range 19-69 years). A smaller female percentage attended the municipal SUD centers $(13 \%)$ compared to the county council unit (28\%). However, no difference was found for being in work/studies or without occupation. The most important difference between the patients attending municipal centers and the county council unit was found in the type of substance use, which is likely to be related to the large difference in age. The initial mean AUDIT score was 12.3 for the municipal patients and 21.6 for the patients attending the county council unit. For DUDIT it was the opposite, with an initial mean score of 22.8 at the municipal centers and only 5.5 at the county council unit. A partial explanation for this large difference in AUDIT scores was the fact that the patients who attended the county council dependency disorder unit for alcohol abstinence treatment, decided to self-refer to the outpatient treatment at the same unit.

The CORE Therapy Assessment form, filled out by the therapists at treatment start $(\mathrm{n}=$ 119), also rated the patients' psychological distress on several problems/concerns using a fivestep Likert scale (Table 2). In addition, neglect during childhood, interpersonal traumas and non-interpersonal traumas were reported on a four-step Likert scale (Table 3). There were significantly higher ratings in therapists' assessments at the county council outpatient unit for anxiety, self-esteem, interpersonal relationships and work/studies, while the municipal outpatient centers rated higher for psychosis and cognitive problems.

Table 2. Therapist ratings of patients' problems/concerns at treatment start (from no problem $=0$, mild $=1$ to severe $=4$ ).

\begin{tabular}{lrr}
\hline Problem/concern (1-4) & n & \% \\
\hline Anxiety/stress & 59 & $50 \%$ \\
Depression & 49 & $41 \%$ \\
Physical problems & 40 & $34 \%$ \\
Self-esteem & 33 & $28 \%$ \\
Interpersonal relationships & 31 & $26 \%$ \\
Trauma/abuse & 13 & $11 \%$ \\
Eating disorder & 10 & $8 \%$ \\
Bereavement/loss & 10 & $8 \%$ \\
Psychosis & 8 & $7 \%$ \\
Personality problems & 8 & $7 \%$ \\
Cognitive/learning & 7 & $6 \%$ \\
\hline Work/studies & 32 & $27 \%$ \\
Living/welfare & 24 & $20 \%$ \\
\hline
\end{tabular}

Table 3. Therapist ratings of patients' problems/concerns at treatment start (from no problem $=0$, small = 1 to large $=3$ ).

\begin{tabular}{lcc}
\hline \multicolumn{1}{c}{ Problem/concern (1-3) } & n & \% \\
\hline Neglect & 22 & $18 \%$ \\
Interpersonal trauma & 15 & $13 \%$ \\
Non-interpersonal trauma & 12 & $10 \%$ \\
\hline
\end{tabular}


In total, 25 patients had a suspected or confirmed ADHD/ADD diagnosis. Twelve patients had a confirmed ADHD/ADD diagnosis, assessed by a psychiatrist or a psychologist. The remaining 13 patients with a suspected ADHD/ADD diagnosis were either on the waiting list for an assessment by a psychiatrist or a psychologist or they did not want to be assessed. They were normally put on the waiting list by the primary health care service, by the therapists in the study or by themselves. Additionally, there were three patients with a confirmed and one with a suspected autism spectrum disorder.

Forty-four percent of the patients were referred by health care and social institutions, while $56 \%$ were self-referred or referred by family members. Sixty-one percent of the patients took some sort of medication. The most common medication was anxiolytics/hypnotics (39\%), followed by anti-depressants (29\%), disulphiram and acamprosate (20\%), methadone and buprenorphine (8\%), and antipsychotics (8\%). Medication for insomnia was given to $23 \%$ of the patients, forming part of the anxiolytics/hypnotics medication already mentioned. Medication for ADHD/ADD was given to $4 \%$ of the patients.

\section{Therapists}

Seven social workers, four female and three male, served as therapists for the study, with the author of this thesis being one of them. They were all trained in Motivational Interviewing at basic level and four also had advanced training, of whom one was a trainer and a second was both a trainer and supervisor. All were trained in Coping Skills Training/Relapse Prevention. Four were also trained in the Community Reinforcement Approach and three in psychodynamic therapy, two with basic training and one with advanced training involving certification as psychotherapist. Two therapists were trained in both of the last-mentioned methods, i.e. CRA and PDT. The therapists had an average experience of six years (2 to 16 years) working with SUD treatment and an average of 8 years (0 to 17 years) of previous experience of psychological and psychosocial treatment. The mean age was 49.6 (range 35 to $60)$.

The treatments included in this thesis were classified in three orientations: directive, reflective and supportive. The majority of the patients (74\%) were given directive-oriented treatment, $15 \%$ reflective, $7 \%$ supportive and $4 \%$ could not be defined. If the statistics are based on the number of sessions, directive was given for $65 \%$ of the sessions, reflective for $32 \%$ and supportive for $3 \%$.

\section{Instruments}

The Alcohol Use Disorders Identification Test (AUDIT; Babor, Higgins-Biddle, Saunders, \& Monteiro, 2001) is an instrument developed by the World Health Organization for identifying persons with hazardous and harmful patterns of alcohol consumption. The instrument is consistent with ICD-10 definitions of alcohol dependence and harmful alcohol use. In this study AUDIT was used as a self-report questionnaire. AUDIT consists of 10 items and has a scoring range from 0 to 4 . The items are divided into three domains: consumption (items 1-3), dependence (items 4-6) and harmful drinking (items 7-10). Cut-off scores for hazardous or harmful alcohol use are 8 for men and 6 for women (Bergman \& Källmén, 2002). 
The short version AUDIT-C (Bush, Kivlahan, McDonell, Fihn, \& Bradley, 1998) consists of the first three AUDIT items, with a maximum score of 12, and measures current alcohol consumption. In this study AUDIT-C was used to measure change in alcohol consumption at treatment end. The AUDIT-C cut-off scores for hazardous consumption of alcohol are 5 or higher for men and 4 or higher for women (Berman, Wennberg, \& Källmén, 2017).

Berman et al. (2017) also suggest using the AUDIT scores to classify the severity of the alcohol use disorders in four zones. Although this cannot replace an SUD diagnosis, the classification may serve as a guide for what kind of treatment to offer:

- Zone 1 (no or small problems): Men $\leq 7$ points, women $\leq 5$ points

- Zone 2 (moderate problems): Men 8-15 points, women 6-13 points

- Zone 3 (large problems, likely to have an SUD diagnosis): Men 16-19 points, women $14-17$ points

- Zone 4 (very large problems, should have an SUD diagnosis): Men 20-40 points, women 18-40 points

Thus the cut-off score for hazardous or harmful alcohol use is between Zones 1 and 2.

The Drug Use Disorders Identification Test (DUDIT; Berman, Bergman, Palmstierna, \& Schlyter, 2005) is an instrument for identifying individuals with problems related to drugs and their consumption patterns. DUDIT consists of 11 items and has a scoring range from 0 to 4 . The items are divided into three domains: dependence (items 1, 4-8), drug related problems (items 2, 10-11) and intensity of use (items 3 and 9). There is also an extension called DUDIT-E (Berman, Bergman, \& Palmstierna, 2007). In the first part of the extended form (DUDIT-Ed), the patient ticked the types of drugs being used. The cut-off scores for the DUDIT form are 6 for men and 2 for women (Berman et al., 2017).

The first four DUDIT items, with a maximum score of 16, relate to drug use and are named DUDIT-C (Sinadinovic, Wennberg, \& Berman, 2014a). DUDIT-C was used in this study to measure change in drug use at treatment end. The DUDIT-C cut-off score for possible problematic use of drugs was set to 1 or higher (Sinadinovic, Wennberg, \& Berman, 2014b).

Similarly to AUDIT, DUDIT can also be used to classify the severity of the drug use disorders for those scoring above cut-off (Berman et al., 2017):

- Drug related problems: Men 6-24 points, women 2-24 points

- Drug dependence: 25-44 points

Clinical Outcomes in Routine Evaluation - Outcome Measure (CORE-OM; Evans et al., 2002) is a patient self-report measure with 34 items measuring psychological distress experienced during the preceding week on a five-point scale ranging from "Not at all" to "Most of the time". The items cover four major problem areas/domains: subjective wellbeing, symptoms (anxiety, depression, physical problems, and trauma), functioning (general functioning, close relationships, and social relationships) and risk (to self and others). The 
scoring is problem-oriented in that higher scores indicate greater distress. The sum score may range from 0 to 40, as the mean of all 34 items is multiplied by 10 . The instrument has shown good internal and test-retest reliability (0.75-0.95), convergent and discriminant validity and sensitivity to change (Mellor-Clark, Barkham, Connell, \& Evans, 1999; Barkham, Mullin, Leach, Stiles, \& Lucock, 2007).

In order to assess change in psychological distress for individual patients, the Reliable Change Index (RCI; Jacobson \& Truax, 1991) was used. The cut-off score used in the present study between the clinical and non-clinical ranges was 13 . A reliable and clinically significant improvement ("recovered") requires a decrease in ratings $\geq 6.3$ and a change from the clinical to the non-clinical range. A reliable improvement requires a reduction in CORE-OM scores $\geq$ 6.3. Unchanged patients are those whose scores change by less than 6.3 points. Impaired patients have an increase in scores $\geq 6.3$ points (Elfström et al., 2013; Holmqvist, Ström, \& Foldemo, 2014).

The CORE assessment comprises the Therapy Assessment form, completed at intake, and the End of Therapy form at the end. On the Assessment form, the therapist provides information about referral, patient demographic data and the nature, severity and duration of presenting problems. The therapist rates the patient's problems/concerns identified on a Likert scale with five steps: no problems (0), through minimal difficulties not disturbing everyday functioning (1), smaller difficulties affecting at least one area but not everyday functioning (2), moderate difficulties within one or more areas combined with effects on everyday functioning (3) to serious difficulties affecting all areas of the patient's life (4). On the End of Therapy form, the therapist reports the results of the treatment, the number of sessions, whether or not the ending was planned, and which types of interventions were provided to the patient. The Swedish translation of the two forms includes some additions regarding SUD and medication.

Patients' global attachment style was measured using the self-report attachment questionnaire Experiences in Close Relationships - Short form (ECR-S; Brennan, Clark, \& Shaver, 1998). This has been translated into Swedish and modified by Broberg and Zahr (2003). In the ECR-S, patients are asked to focus on their closest relationship, in this study classified in six categories: mother, father, sibling, child, partner, and friend. The ECR-S ratings are combined to give two subscales: anxiety and avoidance. The anxiety dimension assesses individual differences in fear of rejection and abandonment, and need for approval from others. The avoidance dimension assesses individual differences in fear of intimacy and interdependence, and need for self-reliance and unwillingness for self-disclosure. There are six items for anxiety and six for avoidance, scored from 1 to 7 . Combining the mean scores for the two dimensions, four categories of attachment style can be assessed (Bartholomew \& Horowitz, 1991). Patients who score less than 3.5 on both scales are considered as having a secure attachment style. Scores $\geq 3.5$ on any of the two dimensions signify an insecure attachment style. Scoring $\geq 3.5$ on the anxiety scale implies a preoccupied attachment style, while a score $\geq 3.5$ on the avoidance scale implies a dismissing attachment style. Scoring $\geq 3.5$ on both scales has been suggested to imply a fearful attachment style. The results are presented as scores on the two continuous dimensions of anxiety and avoidance as well as a 
category classification based on threshold values for the two dimensions, either the four categories secure, preoccupied, dismissing and fearful or the dichotomous secure and insecure classification.

The short version of ECR provides a reliable and valid measure of attachment style (Wei, Russell, Mallinckrodt, \& Vogel, 2007). The patients filled out the ECR-S questionnaire at the beginning and the end of the treatment.

The patient's alliance was measured using the Working Alliance Inventory - Short Form revised (WAI-SR; Hatcher \& Gillaspy, 2006), which consists of 12 items and measures the therapeutic alliance on a seven-point Likert scale. The items can be summed up to give three subscales: bond, task and goal. The instrument in its short form has shown adequate reliability and validity (Munder, Wilmers, Leonhart, Linster, \& Barth, 2010). The therapist's alliance was measured using the Working Alliance Inventory - Short Form (WAI-S; Tracy \& Kokotovic, 1989). The questionnaires were scored by the patient (WAI P) and the therapist (WAI T) directly after each session.

\section{Study design}

Patients who were referred or self-referred for psychological treatment at three SUD outpatient centers from May 2011 to March 2014 were asked to participate. If the patient agreed to participate, she or he received an envelope containing the CORE-OM, WAI-SR, ECR-S, AUDIT and DUDIT/DUDIT-E forms to be completed after the first session. At each subsequent session, the patient completed the CORE-OM form before and the WAI-SR form after the session. At treatment end, the patient completed the ECR-S questionnaire a second time together with the first three items of AUDIT and the first four items of DUDIT which relate to current substance use. The therapists did not have access to patients' questionnaires. Patients were assigned to therapists consecutively, subject to their availability.

The therapists filled out the CORE Therapy Assessment form at treatment start and the End of Therapy form at treatment termination. After each session the therapists filled out their version of WAI-S. Table 4 gives an overview of the study procedure.

Table 4. Overview of how patients $(P)$ and therapists $(T)$ filled out the questionnaires.

\begin{tabular}{lcccc}
\hline \multicolumn{1}{c}{ Instrument } & $\begin{array}{c}\text { Treatment } \\
\text { start }\end{array}$ & $\begin{array}{c}\text { Before each } \\
\text { session }\end{array}$ & $\begin{array}{c}\text { After each } \\
\text { session }\end{array}$ & $\begin{array}{c}\text { Treatment } \\
\text { end }\end{array}$ \\
\hline AUDIT & $\mathrm{P}$ & & & \\
DUDIT/DUDIT-E & $\mathrm{P}$ & & & $\mathrm{P}$ \\
ECR-S & $\mathrm{P}$ & & & \\
CORE Therapy Assessment form & $\mathrm{T}$ & $\mathrm{P}$ & & \\
CORE-OM & & & $\mathrm{P} / \mathrm{T}$ & $\mathrm{T}$ \\
WAI-SR / WAI-S & & & $\mathrm{P}$ \\
CORE End of Therapy form & & & $\mathrm{P}$ \\
AUDIT-C & & & \\
DUDIT-C & & & \\
\hline
\end{tabular}

${ }^{*}$ First session filled out afterwards

The study received approval from the Regional Ethical Review Board in Linköping (2011/165-3). All patients and therapists were properly informed about the study and gave 
their written consent. Patients were told they would receive the same treatment if they chose not to participate.

\section{Data analyses and statistics}

The relationships between psychological distress, different types of SUD, attachment styles and alliance at treatment start were analyzed based on the initial CORE-OM, AUDIT, DUDIT and ECR-S scores. Treatment outcome has been evaluated as the psychological distress measured by CORE-OM at treatment end, and as substance use at treatment end, measured with AUDIT-C and DUDIT-C. Changes in attachment style at treatment end have been investigated by comparing the initial and final ECR-S ratings. A $\chi^{2}$ test $(95 \%$ confidence interval) was used to test the relationships between attachment style and qualitative variables, while ANOVA and ANCOVA tests were used to assess their relationships to metric variables. For dependent data, McNemar's test (McNemar, 1957) was used for dichotomous variables and a t-test for continuous variables. Correlation coefficients and regression with backward elimination were used to investigate relationships between ECR-S scores and psychological distress and substance use. A Reliable Change Index (RCI) was used to test for significance of within-individual CORE-OM gain scores. The mixed model analyses of patient's alliance and psychological distress were performed with SPSS, and the results were confirmed by running the analyses in the Mplus software.

The statistical analyses were performed using SPSS version 23 and 24.

\section{Summary of the results of the included studies}

\section{Paper I}

The purpose of Paper I was to assess the effect of psychological treatment on psychological distress and substance use in SUD outpatients, responding to the following main questions:

- Does psychological treatment reduce psychological distress in SUD outpatients?

- Does psychological treatment reduce substance use?

- What are the outcomes in terms of psychological distress for the different treatment methods in this study?

- What are the outcomes in terms of substance use for the different treatment methods? (added question)

Ratings at treatment start and end were obtained using Clinical Outcomes in Routine Evaluation - Outcome Measure (CORE-OM, $n=100)$, AUDIT-C $(n=49)$ and DUDIT-C $(\mathrm{n}=27)$. CORE-OM mean scores were significantly improved with a moderate effect size (Cohen's $\mathrm{d}=0.59$ ). In total, $14 \%$ of the patients were recovered, $10 \%$ improved and $5 \%$ deteriorated. Both AUDIT-C mean scores and DUDIT-C mean scores were significantly improved, with large effect sizes (Cohen's $d=0.99$ and $d=1.01$ ), for patients with alcohol use and patients using illicit drugs, respectively. There were 49 patients with AUDIT scores above 
the clinical cut-off, who filled out AUDIT-C at treatment end. Similarly, there were 27 patients with DUDIT scores above the cut-off, who filled out DUDIT-C at treatment end.

A subsequent analysis showed that 41 patients scored above AUDIT-C cut-off for hazardous consumption of alcohol (Berman et al., 2017) at start. At treatment end, 21 patients still scored above this cut-off while 20 scored below cut-off. For DUDIT-C, 25 patients scored above zero (cut-off for possible problematic use of drugs, see Sinadinovic et al., $2014 \mathrm{~b}$ ) at start; of those, 11 scored above cut-off and 14 scored zero at treatment end. Figure 1 shows the within-patient results.

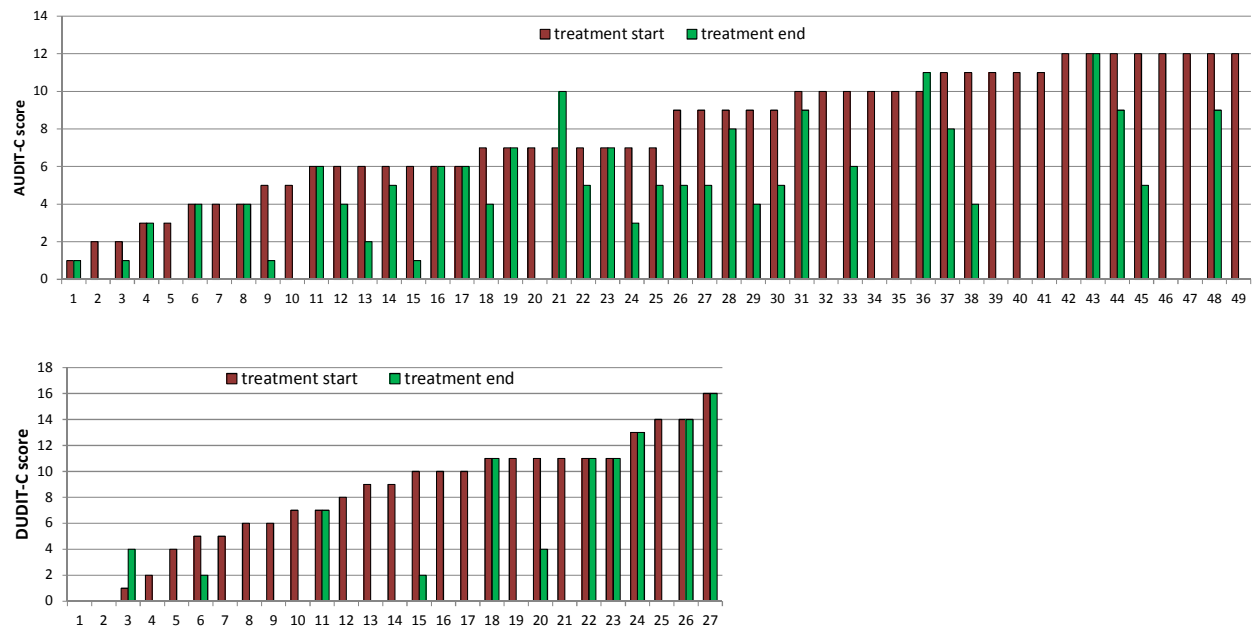

Figure 1. Outcome of AUDIT-C (top) and DUDIT-C (bottom) for patients scoring above AUDIT and DUDIT cut-off at treatment start. Hazardous consumption cut-off for AUDIT-C is 5 points or more for men and 4 points or more for women. The corresponding cut-off for DUDIT-C is 1 point or more for both men and women.

Routine psychological treatment thus showed positive effects on psychological distress as well as on reduction of substance use. However, a substantial number of patients remained unchanged, particularly regarding psychological distress. In part, this can be explained by almost half of the patients $(n=46)$ rating an initial total CORE-OM score below the clinical cut-off, which means that by definition they could not recover.

The therapists reported a wide spectrum of psychological problems on the Therapy Assessment forms, indicating that patients undergoing outpatient treatment care for SUD often suffer from co-occurring disorders. Fifty percent of the 119 patients were assessed as suffering from anxiety and $41 \%$ from mild to severe depression. Other problems reported were physical distress (34\%), problems with self-esteem $(28 \%)$, interpersonal problems $(26 \%)$, trauma $(11 \%)$, eating disorder $(8 \%)$, bereavement/loss $(8 \%)$, psychosis $(7 \%)$, and personality problems $(7 \%)$. Mild to severe neglect during childhood was reported for $18 \%$ of the patients.

It is quite common and recommendable to combine different treatment methods among SUD patients, especially when they show co-occurring disorders. Hence, the majority of the 
patients were treated with more than one psychological method, i.e. by different combinations of therapy types. The effects of different treatment methods were assessed by classifying them into five subgroups. When the differences in final CORE-OM scores of these subgroups were analyzed in an ANCOVA, using initial CORE-OM scores as covariates, no differences were found in outcome for final CORE-OM score between the five treatment categories $\mathrm{F}(4,90)=$ $1.14, \mathrm{p}=.344)$. A $t$-test analysis of pre-post CORE-OM scores showed close to large (Cohen's $d=0.72)$ or large ( $d=0.81)$ effects for reduction in psychological distress for patients treated with RP ( $n=23)$ or RP together with MI $(n=25)$, respectively. For treatments based on PDT $(n=12)$, the reduction in CORE-OM scores was not significant.

A subsequent analysis of outcome on substance use for different treatments is found in Table 5 (alcohol consumption) and Table 6 (drug use), based on all patients who filled out AUDIT-C and DUDIT-C forms at treatment end and who also scored above the cut-off scores in AUDIT and DUDIT at treatment start.

Table 5. Initial and final mean scores and standard deviations in AUDIT-C for different treatments for patients who scored above AUDIT cut-off at treatment start. Results of a t-test of the differences and effect sizes.

\begin{tabular}{lcccccc}
\hline Scale & $\mathrm{n}$ & $\begin{array}{c}\text { Initial } \\
\text { score }\end{array}$ & Final score & $\begin{array}{c}\text { Change } \\
\text { in score }\end{array}$ & $\mathrm{T}(\mathrm{p})$ & $\begin{array}{c}\text { Cohen's } \\
\mathrm{d}\end{array}$ \\
\hline PDT or (PDT and MI and/or other) & 6 & $6.0(3.5)$ & $3.8(3.1)$ & 2.17 & $3.1(.027)$ & 1.26 \\
RP alone & 6 & $6.0(2.4)$ & $4.3(2.6)$ & 1.67 & $1.0(.363)$ & 0.41 \\
RP and MI & 17 & $8.8(2.6)$ & $4.1(3.5)$ & 4.76 & $4.9(<.001)$ & 1.20 \\
RP and MI and other & 12 & $8.3(2.7)$ & $3.3(3.7)$ & 5.00 & $3.6(.004)$ & 1.05 \\
Other treatments not PDT/RP/MI, & 5 & $9.2(4.2)$ & $5.2(5.0)$ & 4.00 & $1.9(.132)$ & 0.84 \\
alone or in combination & & & & & &
\end{tabular}

Note: PDT = Psychodynamic Therapy, $\mathrm{MI}=$ Motivational Interviewing, RP = Relapse Prevention, other $=$ Community

Reinforcement Approach (CRA), Cognitive-Behavioral Therapy (CBT), psycho-educative intervention, crisis intervention, supportive therapy and counselling.

A significant reduction in alcohol consumption was found for PDT alone, PDT with MI and/or other, for RP and MI, and for RP and MI with other.

Table 6. Initial and final mean scores and standard deviations in DUDIT-C for different treatments for patients who scored above DUDIT cut-off at treatment start. Results of a $t$-test of the differences and effect sizes.

\begin{tabular}{lcccccc}
\hline Scale & $\mathrm{n}$ & $\begin{array}{c}\text { Initial } \\
\text { score }\end{array}$ & Final score & $\begin{array}{c}\text { Change } \\
\text { in score }\end{array}$ & T (p) & $\begin{array}{c}\text { Cohen's } \\
\mathrm{d}\end{array}$ \\
\hline PDT or (PDT and MI and/or other) & 2 & $7.5(5.0)$ & $2.0(2.8)$ & 5.50 & $3.7(.170)$ & 2.59 \\
RP alone & 12 & $9.3(3.5)$ & $5.9(5.8)$ & 3.42 & $2.4(.036)$ & 0.69 \\
RP and MI & 5 & $8.6(3.8)$ & $0.8(1.1)$ & 7.80 & $4.1(.014)$ & 1.85 \\
RP and MI and other & 7 & $5.1(4.6)$ & $0.0(0.0)$ & 5.14 & $3.0(.025)$ & 1.13 \\
Other treatments not PDT/RP/MI, & 1 & $16.0(-)$ & $16.0(-)$ & 0.0 & - & - \\
alone or in combination & & & & & &
\end{tabular}

Note: PDT = Psychodynamic Therapy, MI = Motivational Interviewing, RP = Relapse Prevention, other = Community Reinforcement Approach (CRA), Cognitive-Behavioral Therapy (CBT), psycho-educative intervention, crisis intervention, supportive therapy and counselling.

Significant reductions in the use of illicit drugs were obtained for RP alone or in combination with MI and other. For PDT, only two patients scored above the DUDIT cut-off, giving a non-significant gain score in DUDIT-C although the effect size was high. 


\section{Discussion}

The purpose of this practice-based study was to assess the outcome of psychological treatments in routine care for patients with substance use disorder. We raised three main questions, of which the first two addressed the effect of psychological treatment on psychological distress and substance use. The analyses showed that patients were generally improved by the treatments, with regard to both general psychological problems and substance use. The effect size for reductions in alcohol and illicit drug use scores was large, and was higher than for the reduction in psychological distress.

Almost half of the patients had an initial total CORE-OM score below the clinical cut-off, which means that by definition they could not recover, an issue discussed by Lambert and Ogles (2009). Both the initial CORE-OM scores and the final scores were lower than those reported from psychological treatments in primary care (Holmqvist et al., 2014). One interpretation could be that primary care patients and SUD patients come to treatment for different reasons. Primary care patients are usually self-referred and come with acute distress, while patients with SUD are to a large degree - in this study $44 \%$ - referred to treatment by others and not always in an acute phase. It may also be that the SUD patients use alcohol and drugs as self-medication (e.g. Khantzian \& Albanese, 2008), which may hide some of their psychological distress. It should be noted that some of the patients came to therapy during opiate maintenance medication. Half of the patients had some medication related to psychological distress.

The third question raised in the introduction focuses on the effect on psychological distress of the different treatments given. The majority of the patients were treated with more than one psychological method. It is quite common - and recommended - to combine different treatment methods among SUD patients, especially when they show co-occurring disorders. The therapists participating in this study were experienced, which may be an additional explanation for the many different combinations of treatment methods that were used. An overall finding of Paper I was that substance use and psychological distress were reduced for all treatment methods, but for reductions in psychological distress there were larger effects for combinations including relapse prevention (RP).

A striking finding in Paper I was the large number of co-occurring disorders indicated by therapists' assessments. The complexity of patients' problems underlines the importance of working simultaneously with both aspects.

\section{Paper II}

The aim of this study was to assess the attachment style of SUD outpatients in routine care at treatment start and end, and the relationships between attachment style, psychological distress, and substance use. The following research questions were raised:

- Are there any relationships between attachment style and psychological distress in SUD outpatients at treatment start?

- Are there any relationships between attachment style and different types of substance use? 
- Does attachment style predict changes in psychological distress and substance use in psychological treatment?

- Does attachment style change as a result of psychological treatment in SUD outpatients? If so, is it related to the treatment orientation given? (added question)

Patients' ratings using ECR-S at treatment start $(n=108)$ and end $(n=60)$ were analyzed together with treatment outcome for psychological distress and substance use. The ratings for the two ECR-S dimensions of anxiety and avoidance were used to determine the attachment styles classified as secure/insecure or secure/preoccupied/dismissing/fearful. An insecure attachment style was more common among the SUD outpatients, compared to non-clinical groups. Patients with a fearful or preoccupied attachment style at treatment start scored significantly higher on psychological distress than patients with a secure attachment style. The regression analysis showed that the ECR-S dimension of anxiety had a stronger association with the patient's initial psychological distress than the avoidance dimension, both for the CORE-OM total score and for the subscales of subjective well-being, symptoms, functioning and risk self, but not for the subscale risk for other.

There were no differences in attachment styles between the three substance use subgroups alcohol, drugs and both alcohol and drugs.

There were significant differences in final CORE-OM scores between those with a secure and an insecure attachment style, but this difference disappeared when initial CORE-OM scores were introduced as a covariate. The difference in initial attachment styles for those who reliably improved $(n=22)$ and those who were reliably impaired $(n=5)$ was not significant, $\chi^{2}(3)=3.1$, ns. There were no significant correlations between the ECR-S anxiety and avoidance dimensions and the patients' reported changes in alcohol consumption at treatment end. However, the ECR-S dimension avoidance was negatively correlated with the reduction in drug use, implying that patients with higher scores on avoidance showed smaller or no reduction in drug use at treatment end. A subsequent ANOVA analysis of changes in substance use for the secure and insecure subgroups, showed a significantly larger reduction in drug use for patients with a secure attachment (mean $=7.0, \mathrm{n}=13$ ) compared to those with an insecure attachment style (mean $=3.2, \mathrm{n}=15)(\mathrm{t}(1,26)=5.08, \mathrm{p}=.033)$. For reduction in alcohol use, the difference was not significant.

The psychological treatment of SUD patients, in addition to reducing psychological distress and substance use, contributed significantly to changes from insecure to secure attachment style. Of the patients who filled out ECR-S at treatment end $(n=60), 35 \%$ showed a secure attachment style at treatment start and $50 \%$ at treatment end $\left(\chi^{2}(1)=12.38, p<.001\right.$; McNemar's test $=0.049$ ). When the patients answered the question about who they thought of as their closest relationship at treatment start, 52\% reported their partner, $23 \%$ a friend and $11 \%$ their mother. At treatment end, 16 out of 49 patients (11 patients only responded once) reported a change. The movement was between the same three persons as listed above.

Treatment orientations, separated as directive/reflective/supportive, showed some significant differences. For patients receiving a directive treatment, the ECR-S avoidance 
dimension scores decreased (mean change $0.29, \mathrm{n}=43$ ), while those receiving a reflective treatment showed an increase for the avoidance dimension (mean change $-0.70, n=13)(F(2)=$ $3.38, \mathrm{p}=.041)$. A paired sample $t$-test of ECR-S dimensions pre-post showed a significant reduction in the anxiety dimension for those who had received a directive treatment. The changes for the other treatments in this dimension were non-significant. For changes in the avoidance dimension, there were no significant reductions for any of the treatment orientations.

\section{Discussion}

Other studies have shown a higher frequency of insecure attachment styles and patterns among SUD patients in comparison with non-clinical populations. This was confirmed in Paper II. The results also showed a stronger relationship between attachment style and psychological distress than between attachment style and SUD. The SUD patients classified as preoccupied and fearful showed significantly higher psychological distress at treatment start compared to those classified as secure. An insecure attachment pattern or style may contribute to difficulties in regulating emotions and interpersonal relationships. Since this result is based on a correlational analysis of self-reported measures at treatment start, it is not possible to draw any conclusion about the direction of the causal relationship between attachment style and psychological distress.

We expected that patients with a secure attachment style would respond better to psychological treatment compared to those with an insecure attachment style. The results showed that SUD patients with a secure attachment style at treatment start ended treatment with considerably lower psychological distress compared to those who had an insecure attachment style. However, patients with a secure attachment also entered treatment with lower psychological distress, implying less possibility of improvement. Paper II thus could not find larger improvements for patients with a secure attachment style, compared to those with an insecure attachment.

Treatment effects on substance use showed relationships to attachment style for reductions in drug use, but not for alcohol. Patients with high scores on the avoidance dimension showed smaller or no reductions in drug use at treatment end, supporting the conclusion that SUD patients with a dismissing attachment style show poorer treatment outcome. This subgroup has been found to externalize their problems (Schindler \& Bröning, 2015) and has a tendency to respond less to treatment (Winters, Stinchfield, Latimer, \& Stone, 2008).

Another finding of Paper II was a significantly increased proportion of securely attached patients at treatment end, showing the dynamic character of the perceived attachment. This study has reported changes in attachment styles in both directions that may be due to important life events. It could be noted that approximately $30 \%$ reported a different person as their closest relationship at treatment end.

During psychological treatment, the therapist may be perceived as a new attachment figure that contributes to a corrective emotional experience. A change from insecure to secure attachment style can be an important goal for SUD treatment, since it may prevent the patient 
from using defense strategies involving substance use for regulating emotions and interpersonal relationships.

\section{Paper III}

The main aim of Paper III was to assess the relationship between alliance and treatment outcome of SUD patients in routine care and to study the influence of drug type, attachment style, and treatment orientation as potential moderators. Treatment outcome was measured as reduction in substance use and in psychological distress.

First, we investigated possible predictors for alliance. Secondly, we looked at how the alliance relates to different outcomes. Thirdly, we studied three moderators of the allianceoutcome association: type of substance use, attachment style, and treatment orientation. Finally, we analyzed session-to-session data associations between alliance - with and without patient-centering of the data - and psychological distress.

There were weak or no associations between the patient- and therapist-rated alliance and treatment outcome, as measured by reductions in substance use and psychological distress. However, there were significant correlations between patients' alliance and psychological distress from session-to-session, indicating that patients with a high alliance at one session showed lower psychological distress at the next session. After patient-centering of the data, most of this relationship disappeared, showing that it was predominantly due to betweenpatient effects. Thus patients with a generally high alliance level also scored lower in terms of psychological distress. The mixed model analysis also showed that the correlation between alliance variations and psychological distress at the next session disappeared when controlling for psychological distress at the previous session.

\section{Discussion}

The results of the analyses show that the relationships between alliance and outcome, when using mean alliance ratings, were weak. The results were similar when outcome was assessed as a decrease in substance use and psychological distress. These results strengthen the conclusion from the meta-analyses of Flückiger et al. $(2013,2018)$ of a weak connection between alliance and outcome for SUD patients.

Considering type of substance use as a moderator of the alliance-outcome association, there was a significant positive correlation between therapist-rated alliance and reduction in alcohol consumption for the group only using alcohol. The results indicate that for the alcohol group, the therapists' alliance was associated with a reduction in alcohol consumption. These patients who only use alcohol were older, with a longer history of alcohol problems. The patients who only used drugs were much younger. Most of them used cannabis, and a smaller group used opiates.

It is of interest to note that, while looking at attachment style as a moderator, there was also a positive relationship between therapist-rated alliance and reduction in alcohol consumption for patients with an insecure attachment style, in line with the findings of Zack et al. (2015). 
For the patients using drugs with a secure attachment style, the therapist rated a high alliance for patients who did not reduce their drug use. Scrutinizing the data, there were a small number of young male patients $(n=3)$ principally using cannabis who did not respond to the treatment. One interpretation is that they were still in a phase of experimental use. It seems that for this particular group of patients, therapists might experience a strong alliance although they did not decrease their drug abuse.

The final moderator analyzed was treatment orientation. For outcome of substance use and psychological distress, there were no significant correlations for any of the treatment orientations. A somewhat surprising result is that therapist-rated alliance to patients given a reflective treatment did not show a significant relationship to psychological distress, since psychodynamic orientation focuses on the relationship between the therapist and the patient. As mentioned before, the mean levels of both patient- and therapist-rated alliance were significantly lower for reflective treatment compared to directive treatment.

We found three predictors for alliance: living alone/with others, level of education and therapist rating of patient's motivation at treatment start. Patients living with others had a better alliance. In the present study, therapist-rated alliance was higher for patients with higher education (university) level, compared to patients who had not completed their upper secondary diploma, which is in line with Belding et al. (1997). This finding suggests that the socioeconomic status of the patient being different from that of the therapist is a factor to take into consideration. This issue could be discussed more in treatment research. The third predictor that was identified, the therapist initial rating of the patient's motivation to change, has been highlighted in earlier studies (Meier et al., 2005a; Meier et al., 2005b; Winters et al., 2011).

When correlations were analyzed on a session-to-session basis, moderate associations were found between patient-rated alliance and psychological distress. The correlations were somewhat weaker for patient-centered alliance scores, indicating that it was the general level of the alliance that correlated with symptom level at the next session rather than the ipsative (patient-centered) score. This finding might suggest that the association between alliance and outcome was due to the general level of psychological problems. A low rating of the alliance might indicate more psychological problems, just like a high rating in CORE-OM.

This interpretation was reinforced by the results from the mixed models analyses. These analyses suggested that when the model showing an association between alliance at the end of the session and the symptom level at the start of the next session, was supplemented by the CORE-OM rating at the start of the session when alliance was rated, the correlation was no longer significant. A possible interpretation could be that both alliance ratings and CORE-OM ratings capture the patient's general level of psychological distress, but there were no causal ties between alliance and symptom level.

The results of the mixed model analysis, performed in SPSS, were confirmed by an analysis with a dynamic structural equations modelling in Mplus: the average effect of alliance on symptom reduction when the preceding CORE scores were entered in the model was non-significant. However, an interesting finding of the Mplus analysis was that the 
variation in this effect between patients was significant, indicating that it might be meaningful to explore other variables that might moderate the association between alliance and symptom reduction.

\section{General discussion}

The aim of this thesis was to evaluate the effects of community-based psychological treatment on SUD outpatients' psychological distress and substance use, and to analyze the importance of their attachment style and the alliance in terms of treatment outcome.

The findings show a large degree of heterogeneity among SUD patients attending routine care, in terms of e.g. types of substance abuse and age, but also - in line with many other studies - co-occurring disorders. This underlines the need for not having too narrow a perspective on SUD treatments, limited to a reduction in the abuse of alcohol and illicit drugs. There is consensus on the need to treat SUD and psychological problems simultaneously (Mueser, Noordsy, Drake, \& Fox, 2003; Kelly, Daley, \& Douaihy, 2012). This motivates an integrated treatment approach where SUD patients are offered treatments within the context of multiple competences, likely most appropriate within psychiatric care.

The responsibility for SUD treatment in Sweden is shared principally by the county councils and the municipalities. The Swedish Government Official Report (SOU 2011:35, 2011) recommended that county councils should assume full responsibility for SUD treatment. However, the political decision was to continue with shared responsibility, although the patient reports said that 9 out of 10 Swedish citizens with SUD preferred to consult county council medical care for SUD (SOU 2011:35, 2011). Individuals with SUD who receive medical treatment, counselling, or psychological treatment at the county council dependency disorder units can be treated by physicians, psychiatrists, nurses, psychologists, psychotherapists and social workers. These patients get an SUD diagnosis, and in some cases also other psychiatric diagnoses. Individuals who receive psychological treatment at the municipal SUD outpatient centers will mainly be treated by social workers and psychotherapists. They do not usually receive an ICD-10 or DSM-5 diagnosis. A reasonable assumption is that the shared responsibility between county councils and municipalities will make an integrated SUD treatment more difficult. Another consequence of the present system is that research on the outcome of SUD treatments will be more difficult, since the research community will request that the patients are formally diagnosed. Integrated treatment at county council level would also make it easier for the patients to receive medical care.

The heterogeneity of the patients, as well as of the treatments given, made the outcome assessment difficult. On the other hand, a naturalistic study may give a real-world picture of SUD treatments. One reason for the heterogeneity of the treatment methods is probably the fact that the patients were treated by experienced therapists who selected the most appropriate combination of methods that they mastered.

The instruments used to assess outcome in terms of substance use and psychological distress generated information with certain limitations. For a number of patients, their ratings 
of psychological distress (CORE-OM) were in the normal range at treatment start, which implies that it may be difficult to determine whether they improved. This problem has also been pointed out by Lambert and Ogles (2009). In a psychodynamic framework, this could possibly be understood as an effect of split and denial based on the structure of defense of the patient's personality. It could also be a result of cognitive deficits, innate or as a consequence of substance abuse. It is hard to believe that a serious problem with alcohol and/or illicit drugs would not have an impact on patients' mental health and social relations.

The outcome of substance use was only measured by changes in the consumption of alcohol or use of illicit drugs from treatment start to end. One difficulty in terms of evaluation was that, when treatment started, some of the patients were already abstaining from alcohol, on medication (e.g. Antabuse) or in a maintenance program for opiate dependence, and thus reported no substance use at treatment start. Despite these shortcomings contributing to lower initial scores for both psychological distress and substance use, the results show significant reductions at treatment end.

The patient's attachment style may be of importance concerning how the patient benefits from the treatment through the collaboration with the therapist. A secure attachment is considered to be a protector and a facilitator for overcoming difficulties and strain, e.g. crises during the lifecycle. An insecure attachment is common among SUD patients, and this condition involves obstacles in developing a fruitful collaboration with the therapist. Having an insecure attachment often means difficulties in the ability to mentalize, i.e., to look upon oneself from outside and others from inside. An insecurely attached person can be seen as more rigid in her or his thinking, with a lower tolerance for ambiguity, and as more difficult to reach in a psychological treatment context. It can be hard to take in, and in the long run internalize, a more flexible way of thinking about herself or himself and others. A major task of the therapeutic work is, in this way of thinking, to obtain epistemic trust, i.e. the patient's willingness to consider new knowledge from the therapist as trustworthy and to make it her or his own (Fonagy \& Allison, 2014). This is in line with the ideas of Bowlby (1988), who saw the therapeutic relationship as an opportunity to change the internal working models. Some authors have suggested that a modification of patients' attachment style may be seen as a significant treatment goal in its own right (Meyer \& Pilkonis, 2002).

An important finding in the present study was the increased proportion of securely attached patients at treatment end. One might speculate that these patients no longer use defense strategies involving substance use for regulating emotions, interpersonal relationships, and threats that activate the attachment system. The internal working models may have changed as a result of the treatment, and the relationship with the therapist has become a corrective emotional experience (Alexander \& French, 1946; Mallinckrodt, 2010).

It may be essential for the therapist to take knowledge about the patient's attachment style or pattern at treatment start, independently of the treatment modality chosen, as it may help to decide which type of treatment method and therapeutic stance that would be preferable.

The role of the therapeutic alliance in SUD treatments remains unclear, but various metaanalyses have reported weaker associations between alliance and treatment outcome among 
SUD patients. We found a significant negative relationship between patient-rated mean alliance and the patient's psychological distress levels at start, end, and as an average during treatment, showing that high levels of psychological distress go together with low alliance levels. When session-to-session alliance and psychological distress data were analyzed, a strong negative correlation was found, however the strong relationship disappeared when patient-centered alliance data were used. The findings suggest that the alliance ratings might be indicators of the patient's psychological well-being in general, rather than predicting the psychological distress at the next session.

A better relationship between a high alliance at one session and decreased psychological distress at the next session would have indicated that the patient had left the therapeutic session and practiced her or his new cognitive and relational skills in a benign social environment, according to the arguments suggested by Fonagy and Allison (2014). They based their ideas on a patient's capacity to mentalize according to her or his attachment style or pattern. In this study of SUD patients, it was not possible to find any moderating role of the different attachment styles for outcome in psychological distress. The explanation for the weaker relationships between alliance and treatment outcome among SUD patients seems to be due to other factors e.g. those discussed in the introduction of the thesis (Alliance and SUD section). An analysis of session-to-session data performed in Paper III indicated that it might be meaningful to explore other variables that have effect on the alliance-outcome association. It is noteworthy that the relative importance of alliance for the outcome of psychological treatment has been estimated at $7-8 \%$ of the total variance, while patient factors are estimated at 30-40\% (Norcross \& Lambert, 2011; Lambert \& Barley, 2002).

Measures of alliance and e.g. psychological distress on a session-to-session basis provide important information about work progress in psychological treatment. It is of paramount importance to pay attention to decreased alliance, which can be interpreted as a rupture in the relationship between the patient and the therapist (Safran, Muran, \& Eubanks-Carter, 2011; Aguirre McLaughlin, Keller, Feeny, Youngstrom, \& Zoellner, 2014). If the therapist tries to repair this rupture, a negative development might be avoided which, in the worst case, may lead to the patient leaving treatment. Obtaining feedback by monitoring the alliance and psychological distress is thus a way of preventing the patient from deteriorating and, ultimately, dropping out. Getting back on track has shown to be beneficial in studies by Lambert and Shimokawa (2011) and Shimokawa, Lambert and Smart (2010). Incorporating online questionnaires as part of SUD treatment in routine care could probably improve retention in treatment.

There seems to be a certain resistance among therapists towards assessing the outcomes of their work in routine practice (Jensen-Doss \& Hawley, 2010) and participating in research studies (Taubner, Klasen, \& Munder, 2016). This resistance was also seen at management level at some clinics and SUD outpatient centers when this study was initiated. It is important to perform a deeper analysis of the reasons behind these issues, in order to pave the way for more research studies and for outcome assessments to become a natural part of psychological treatment of SUD patients and other patients. 
A great deal of work to improve SUD treatment has been carried out during the last few decades in Sweden by the National Board of Health and Welfare, materialized in the Swedish national guidelines for SUD treatment (Socialstyrelsen, 2017). However, a common structure for monitoring the results is still lacking, according to a report by the Swedish Agency for Health and Care Services Analysis (2016). As the guidelines have been accepted by the SUD treatment centers, it should be possible to integrate outcome assessments on a regular basis. Confirmation that the treatments provided produce some kind of results would be of benefit for the organization, the therapist and, in particular, the patient who asks for support for a better way of living.

\section{Strengths and limitations}

The naturalistic design entails good external validity, as the treatments correspond with what SUD patients usually receive in routine care. However, a number of limitations need to be commented on. The internal validity is low with regard to method adherence. On the other hand, it can be argued that therapists' reports of treatments provided have an external validity as the treatments are given in accordance with common practice. Naturalistic studies are, despite commonly lacking control groups, important complements to RCT studies (Barber, 2009). It has been shown that results from naturalistic studies are easy for clinicians to accept and put into practice.

The heterogeneity of SUD patients, e.g. in terms of age, gender, type and severity of substance use, psychological distress and treatment length is a problem for the analyses and larger samples would make results more reliable. The importance of socioeconomic status has not been taken into account, except indirectly through variables like occupation/ studies/employment status etc. There is also a need for long-term follow-up of treatment results, which was not feasible within this study design.

In Sweden, considerably more men have SUD compared to women. Of those with problematic use of alcohol, $35 \%$ are women and for use of illicit drugs $25 \%$ are women. As a consequence of this, men are overrepresented in SUD treatments. The proportion of women participating in this study (22\%) was lower. The fact that the women had a higher mean age (40.0 years) compared to men (33.5 years) may indicate that women come to treatment later. However, this and other studies of SUD treatment show no differences in outcome between women and men.

All analyses were carried out on self-reported data, which assume that patients provide reliable answers. Studies using self-reports from SUD patients have been shown to correlate highly with other corresponding data sources (Secades-Villa \& Fernández-Humida, 2003).

The patients reported their substance use at the start and end of treatment, leading to loss of data for unplanned endings. More frequent self-report measures, together with complementary biological markers and qualitative measures, would have strengthened the analyses. 
Various treatment methods were represented in the study, often in different combinations which made the classification of treatment orientations rather complex. Moreover, there were methods that were not included, e.g. Twelve-step program, Motivational Enhancement Therapy, Acceptance and Commitment Therapy, Couple Therapy, Group Therapy and Internet treatments. For better statistical power in the evaluation of different treatments, a larger sample would have been required.

Very few - if any - studies have been reported on changes in attachment style following psychological treatment of SUD patients. The study results would have been stronger if the reported attachment styles based on self-report questionnaires had been combined with assessments from attachment interviews. It could also have been of interest to measure the therapist's attachment style (Dozier, Cue, \& Barnett, 1994), as well as the patient's attachment to the therapist (Mallinckrodt, Gantt, \& Coble, 1995).

\section{Clinical implications and future perspective}

This thesis shows the need to deepen our understanding of the processes between SUD patients and therapists in psychological treatment. These patients vary with regard to type of SUD as well as concerning their psychological and social characteristics. Studies based on large samples in naturalistic settings may offer opportunities to detect patient variables that may moderate treatment success in different treatment forms. These could be supplemented with qualitative studies and mixed method designs.

The study has generated session-to-session information on psychological distress and alliance perceived by both patients and therapists. By video filming the treatment sessions, information could also be gained about processes in the interaction between the patient and the therapist such as alliance trajectories and rupture-repair patterns, and the significance of the patient's attachment style for the interaction. Attachment can be measured, not only at baseline with interviews and/or self-reporting, but also with new methods measuring dynamic patterns within the treatment (Daniel, 2014; Talia, Miller-Bottome, \& Daniel, 2017).

The current trend in psychotherapy research is to emphasize the study of change mechanisms. In this study, it was found that the treatment alliance did not account for the same share of outcome variance that has been found in other treatment contexts. It corroborated previous findings in SUD treatment in this area. Alliance studies have moved from the simple study of associations between alliance and outcome to more elaborate analyses of moderators of the alliance and studies of fluctuations and problems in the alliance.

Our knowledge is still scarce about factors important for SUD treatment outcome. It is a field that needs further exploration with larger samples, additional instruments and methods.

A continued implementation of the national guidelines for SUD treatment in routine care together with a permanent outcome evaluation system would generate important benefits for patients, therapists and future research. 


\section{Acknowledgements}

This thesis was financed by research grants from the Regional Council in Östergötland, Sweden and support from the Department of Dependency Disorders, Vrinnevi Hospital, Norrköping, Sweden.

First of all I would like to thank all the participating patients and therapists for your persistent collaboration. Together you have answered or rated 158347 questions.

There is one specific person who made this thesis possible and to whom I am very grateful: Ursula Thienemann, Head of the Department of Dependency Disorders at Vrinnevi Hospital in Norrköping. "Varför nöja dig med keps när du kan få en hatt?" was your comment at the beginning of my studies. Thank you for trusting me!

Björn Philips, my co-supervisor during the first years and my main supervisor during the final part of my doctoral studies: You are so good at structure and keeping it all together, and finding appropriate journals for publishing our papers. Your experiences from work and research on SUD patients, together with your critical eye, have been very valuable and important for my work with the thesis. Above all you are a wise, open and positive person.

Rolf Holmqvist, my supervisor in clinical work for many years and the one who opened the research window for me. You were my main supervisor during my first four years, and you have continued as my co-supervisor for the last few years. Your genuine enthusiasm for science, together with your inexhaustible energy, has been fundamental to my opportunities to advance in my thesis work. You are such a kind and relational person, always willing to share your deep knowledge.

I also owe gratitude to Gerhard Andersson, who reviewed and commented on my results at the half-time seminar, and to Claudia Fahlke, my reviewer at the final seminar. Your comments and suggestions have helped me to improve the thesis in many ways.

Many thanks to my research colleagues at IBL: Annika Ekeblad, Fredrik Falkenström, Erika Viklund, Tommy Skjulsvik, Clara Möller, Mattias Holmqvist Larsson, My Frankl, Börje Lech, Anna-Karin Åkerman, Calle Uckelstam, Malin Bäck, Paul Bergman and Anneli Frostell. I'm very grateful for the administrative support given by Britt-Marie Alfredsson.

Thanks to my colleagues at the Department of Dependency Disorders, for your interest and never-ending support for my research project.

To my cousin Eva Hillgren and my childhood friend Anita Pettersson, who during long phone conversations have encouraged me not to give up; and to all my friends here in Östergötland who have helped me not to forget that there are things in life outside MS Windows and SPSS. Thank you!

To my children Patricia and Pontus, my son-in-law Marc and my grandchildren Joel and Erik: You bring such happiness and sunshine into my life!

Finally, Lars my best friend: your support and love made this journey possible. 


\section{References}

Abbass, A. A., Kisely, S. R., Town, J. M., Leichsenring, F., Driessen, E., De Maat, S., Gerber, A., Dekker, J., Rabung, S., Rusalovska, S., \& Crowe, E. (2014). Short-term psychodynamic psychotherapies for common mental disorders. Cochrane Database of Systematic Reviews, 4. https://doi.org/10.1002/14651858.CD004687.pub4

Adamson S. J., Todd, F. C., Sellman, D., Huriwai, T., \& Porter, J. (2006). Coexisting psychiatric disorders in a New Zealand outpatient alcohol and other drug clinical population. Australian and New Zealand Journal of Psychiatry, 40, 164-170. https://doi.org/10.1080/j.1440-1614.2006.01764.x

Aguirre McLaughlin, A. A., Keller, S. M., Feeny, N. C., Youngstrom, E. A., \& Zoellner, L. A. (2014). Patterns of therapeutic alliance: Rupture-repair episodes in prolonged exposure for posttraumatic stress disorder. Journal of Consulting and Clinical Psychology, 82, 112 121. https://doi.org/10.1037/a0034696

Ainsworth, M. D. S. (1989). Attachment beyond infancy. American Psychologist, 44, 709716. https://doi.org/10.1037//0003-066X.44.4.709

Ainsworth, M. D. S., Blehar, M. C., Waters, E., \& Wall, S. (1978). Patterns of attachment: A psychological study of the strange situation. Hillsdale, NJ: Lawrence Erlbaum. https://doi.org/10.4324/9780203758045

Alexander, F. G., \& French, T. M. (1946). Psychoanalytic therapy: Principles and applications. New York, NY: Ronald Press Company. https://doi.org/10.1001/jama.1948.02890470070030

Allen, J. P., McElhaney, K. B., Kuperminc, G. P., \& Jodl, K. M. (2004). Stability and change in attachment security across adolescence. Child Development, 75, 1792-1805.

Allen, R. S., \& Olson, B. D. (2016). The what and why of effective substance abuse treatment. International Journal of Mental Health and Addiction, 14, 715-727. https://doi.org/10.1007/s11469-015-9599-1

American Psychiatric Association. (2000). Diagnostic and statistical manual of mental disorders (4th ed., text rev.). Washington, DC: Author.

American Psychiatric Association. (2013). Diagnostic and statistical manual of mental disorders (5th ed.). Washington, DC: Author.

Babor, T., Higgins-Biddle, J. C., Saunders, J. B., \& Monteiro, M. G. (2001). AUDIT. The alcohol use disorders Identification Test. Guidelines for use in primary care. Second ed. WHO.

Baldwin, S. A., \& Imel, Z. E. (2013). Therapist effects: findings and methods. In Lambert MJ, editor. Bergin and Garfield's handbook of psychotherapy and behavior change. 6th ed. Wiley; New York: 2013. pp. 258-297. 
Bakersman-Kranenburg, M. J., \& van IJzendoorn, M. H. (2009). The first 10,000 adult attachment interviews: Distributions of adult attachment representations in clinical and non-clinical groups. Attachment and Human Development, 11, 405-417. https://doi.org/10.1080/14616730902814762

Barber, J. P. (2009). Toward a working through of some core conflicts in psychotherapy research. Psychotherapy research, 19, 1-12. https://doi.org/10.1080/10503300802609680

Barber, J. P., Luborsky, L., Crits-Christoph, P., Thase, M. E., Weiss, R., Frank, A., ...\& Gallop, R. (1999). Therapeutic alliance as a predictor of outcome in treatment of cocaine dependence. Psychotherapy Research, 9, 54-73. https://doi.org/10.1080/10503309912331332591

Barkham, M., Mullin, T., Leach, C., Stiles, W. B., \& Lucock, M. (2007). Stability of the CORE-OM and BDI-I prior to therapy: Evidence from routine practice. Psychology and Psychotherapy: Theory, Research and Practice, 80, 267-278. https://doi.org/10.1348/147608306X148048

Barrowclough, C., Meier, P., Beardmore, R., \& Emsley, R. (2010). Predicting therapeutic alliance in clients with psychosis and substance misuse. Journal of Nervous and Mental Disease, 198, 373-377. https://doi.org/10.1097/NMD.0b013e3181da4d4e

Bartholomew, K. (1990). Avoidance of intimacy: an attachment perspective. Journal of Social and Personal Relationships, 7, 147-178. https://doi.org/10.1177/0265407590072001

Bartholomew, K., \& Horowitz, L. M. (1991). Attachment styles among young adults: A test of a four-category model. Journal of Personality and Social Psychology, 61, 226-244. https://doi.org/10.1037//0022-3514.61.2.226

Bates, M. E., Bowden, S. C., \& Barry, D. (2002). Neurocognitive impairment associated with alcohol use disorders: implications for treatment. Experimental and Clinical Psychopharmacology, 10, 193-212.

Belding, M. A., Iguchi, M. Y., Morral, A. R., \& McLellan, A. T. (1997). Assessing the helping alliance and its impact in the treatment of opiate dependence. Drug and Alcohol Dependence, 48, 51-59. https://doi.org/10.1016/S0376-8716(97)00103-8

Bender, K., Springer, D. W., \& Kim, J. S. (2006). Treatment effectiveness with dually diagnosed adolescents: A systematic review. Brief Treatment and Crisis Intervention, 6 , 177-205. https://doi.org/10.1093/brief-treatment/mhl001

Berglund, K. (2009). Socially stable alcoholics: what characterizes them? Drinking pattern, personality and health aspects of psychosocial and clinical importance. Doctoral Thesis, Department of Psychology, University of Gothenburg, Sweden (ISBN: 978-91-628-76692).

Berglund, K., \& Fahlke, C. (2011). Personlighetens betydelse för missbruk och beroende. In J Frank \& I Nylander. Beroendemedicin. Lund: Studentlitteratur, pp 25-31. (in Swedish) 
Berglund, K., Fahlke, C., Berggren, U., Eriksson, M., \& Balldin, J. (2006). Personality profile in type 1 alcoholism: long duration of alcohol intake and low serotonergic activity are predictive factors of anxiety proneness. Journal of Neural Transmission, 113, 1287-1298. https://doi.org/10.1007/s00702-005-0412-3

Bergman, H., \& Källmén, H. (2002). Alcohol use among Swedes and a psychometric evaluation of the Alcohol Use Disorders Identification Test. Alcohol \& Alcoholism, 37, 245-251. https://doi.org/10.1093/alcalc/37.3.245

Berman, A. H., Bergman, H., Palmstierna, T., \& Schlyter, F. (2005). Evaluation of the Drug Use Disorders Identification Test (DUDIT) in criminal justice and detoxification settings and in a Swedish population sample. European Addiction Research, 11, 22-31. https://doi.org/10.1159/000081413

Berman, A. H., Bergman, H., \& Palmstierna, T. (2007). DUDIT-E The Drug Use Disorders Identification Test-E Manual (in Swedish). Stockholm: Karolinska Institutet.

Berman, A. H., Wennberg, P., \& Källmén, H. (2017). AUDIT \& DUDIT - Identifiera problem med alkohol och droger (in Swedish). Stockholm: Gothia Fortbildning AB.

Bertrand, K., Brunelle, N., Richer, I., Beaudoin, I., Lemieux, A., \& Ménard, J. M. (2013). Assessing covariates of drug use trajectories among adolescents admitted to a drug addiction center: mental health problems, therapeutic alliance, and treatment persistence. Substance Use \& Misuse, 48, 117-128. https://doi.org/10.3109/10826084.2012.733903

Bohman, M., Cloninger, R., Sigvardsson, S., \& von Knorring, A-L. (1987). The genetics of alcoholism and related disorders. Journal of Psychiatric Research, 21, 447-452. https://doi.org/10.1016/0022-3956(87)90092-6

Bordin, E. S. (1975). The working alliance: Basis for a general theory of psychotherapy. Paper presented at the Society for Psychotherapy Research, Washington, DC.

Bordin, E. S. (1989). Building therapeutic alliances: The base for integration. Paper presented at the Society for Psychotherapy Research, Berkley, CA.

Bordin, E. S. (1994). Theory and research on the therapeutic working alliance: New directions. In A. O. Horvath \& L. S. Greenberg (Eds.). The working alliance: Theory, research, and practice (pp. 13-37). New York: Wiley.

Boschloo, L., Vogelzangs, N., Smit, J. H., van den Brink, W., Veltman, D. J., Beekman, A. T. F., \& Penninx, B. W. J. H. (2011). Comorbidity and risk indicators for alcohol use disorders among persons with anxiety and/or depressive disorders: findings from the Netherland Study of Depression and Anxiety (NESDA). Journal of Affective Disorders, 131, 233-242. https://doi.org/10.1016/j.jad.2010.12.014

Bowlby, J. (1958). The nature of a child's tie to his mother. International Journal of PsychoAnalysis, 39, 350-373. 
Bowlby, J. (1960a). Separation anxiety. International Journal of Psycho-Analysis, 41, 89113.

Bowlby, J. (1960b). Grief and mourning in infancy and early childhood. The Psychoanalytic Study of the Child, 15, 3-39.

Bowlby, J. (1969). Attachment and loss, Vol. 1 Attachment. New York, NY: Basic Books.

Bowlby, J. (1988). A secure base: Parent-child attachment and healthy human development. New York, NY: Basic Books.

Brady, T. M., Rierdan, J., Peck, W., Losardo, M., \& Meschede, T. (2003). Post-traumatic stress disorder in adults with serious mental illness and substance abuse. Journal of Trauma and Dissociation, 4, 77-90. https://doi.org/10.1300/J229v04n04_06

Brennan, A., Clarke, C. L., \& Shaver, P. R. (1998). Self-report measurement of adult attachment: an integrative overview. In J. A. Simpson, \& W. S. Rholes (Eds.) Attachment theory and close relationships. (pp. 46-76). New York: Guilford Press.

Broberg, A., \& Zahr, M. (2003). Erfarenheter av nära relationer. Translation to Swedish of Experiences in Close Relationships (Brennan, Clarke \& Shaver, 1998).

Bush, K., Kivlahan, D. R., McDonell, M. B., Fihn, S. D., \& Bradley, K. A. (1998). The AUDIT alcohol consumption questions (AUDIT-C): an effective brief screening test for problem drinking. Ambulatory Care Quality Improvement Project (ACQUIP). Archives of Internal Medicine, 158, 1789-1795.

CAN (2014). Drogutvecklingen i Sverige 2014, CAN Rapport nr. 144. http://www.can.se/contentassets/3f30e3b70ebb461c928fdcdd5a0c3606/drogutvecklingeni-sverige-2014.pdf (in Swedish)

Carroll, K. M. (1998). A Cognitive-Behavioral Approach: Treating Cocaine Addiction. National Institute on Drug Abuse, NIH Publication Number 98-4308.

Castel, S., Rush, B., Urbanoski, K., \& Toneatto, T., (2006). Overlap of clusters of psychiatric symptoms among clients of a comprehensive addiction treatment service. Psychological Addiction Behavior, 20, 28-35. https://doi.org/10.1037/0893-164X.20.1.28

Chopic, W. J., Edelstein, R. S., \& Fraley, R. C. (2013). From the cradle to the grave: age differences in attachment from early adulthood to old age. Journal of Personality, 81, 171183. https://doi.org/10.1111/j.1467-6494.2012.00793.x

Cloninger, C. R., Sigvardsson, S., \& Bohman, M. (1996). Type I and Type II Alcoholism: An update. Alcohol Health \& Research World, 20, 18-23.

Connors, G. J., Carroll, K. M., DiClemente, C. C., Longabaugh, R., \& Donovan, D. M. (1997). The therapeutic alliance and its relationship to alcoholism treatment participation and outcome. Journal of Consulting and Clinical Psychology, 65, 588-598. 
Connors, G. J., DiClemente, C. C., Dermen, K. H., Kadden, R., Carroll, K. M., \& Frone, M. R. (2000). Predicting the therapeutic alliance in alcoholism treatment. Journal of Studies on Alcohol, 61, 139-149.

Cozzarelli, C., Karafa, J. A., Collins, N. L., \& Tagler, M. J. (2003). Stability and change in adult attachment styles: associations with personal vulnerabilities, life events and global construals of self and others. Journal of Social and Clinical Psychology, 22, 315-346. https://doi.org/10.1521/jscp.22.3.315.22888

Crits-Christoph, P., Gallop, R., Temes, C. M., Woody, G., Ball, S. A., Martino, S., \& Carroll, K. M. (2009). The alliance in motivational enhancement therapy and counseling as usual for substance use problems. Journal of Consulting and Clinical Psychology, 77, 11251135. https://doi.org/10.1037/a0017045

Crits-Christoph, P., Gibbons, M. B., Hamilton, J., Ring-Kurtz, S., \& Gallop, R. (2011). The dependability of alliance assessments: the alliance-outcome correlation is larger than you might think. Journal of Consulting and Clinical Psychology, 79, 267-278. https://doi.org/10.1037\%2Fa0023668

Crits-Christoph, P., Johnson, J. E., Connolly Gibbons, M. B., \& Gallop, R. (2013). Process predictors of the outcome of group drug counseling. Journal of Consulting and Clinical Psychology, 81, 23-34. https://doi.org/10.1037/a0030101

Dalton, E. J., Cate-Carter, T. D., Mundo, E., Parikh, S. V., \& Kennedy, J. L. (2003). Suicide risk in bipolar patients: The role of comorbid substance use disorders. Bipolar Disorder, 5, 58-61.

Daniel, S. I. F. (2006). Adult attachment patterns and individual psychotherapy: A review. Clinical Psychology Review, 26, 968-984. https://doi.org/10.1016/j.cpr.2006.02.001

Daniel, S. I. F. (2011). Adult attachment insecurity and narrative processes in psychotherapy: an exploratory study. Clinical Psychology and Psychotherapy, 18, 498-511. https://doi.org/10.1002/cpp.704

Daniel, S. I. F. (2014). Adult attachment in a treatment context: relationship and narrative. London: Routledge.

Dansky, B. S., Saladin, M. E., Coffey, S. F., \& Brady, K. T. (1997). Use of self-report measures of crime-related posttraumatic stress disorder with substance use disordered patients. Journal of Substance Abuse Treatment, 14, 431-437.

Davila, J., \& Cobb, R. J. (2003). Predicting change in self-reported and interviewer-assessed adult attachment: Tests of the individual difference and life stress models of attachment change. Personality and Social Pscyhology Bulletin, 29, 859-870.

https://doi.org/10.1177\%2F0146167203029007005 
De Weert-Van Oene, G. H., De Jong, C. A., Jörg, F., \& Schrijvers, G. J. (1999). The helping alliance questionnaire: psychometric properties in patients with substance dependence. Substance Use \& Misuse, 34, 1549-1569.

Del Re, A. C., Flückiger, C., Horvath, A. O., Symonds, D., \& Wampold, B. E. (2012). Therapist effects in the therapeutic alliance-outcome relationship: a restricted-maximum likelihood meta-analysis. Clinical Psychology Review, 32, 642-649. https://doi.org/10.1016/j.cpr.2012.07.002

DeRubeis, R. J., \& Feeley, M. (1990). Determinants of change in cognitive therapy for depression. Cognitive Therapy and Research, 14, 469-482. https://doi.org/10.1007/BF01172968

Diener, M.J. \& Monroe, J.M. (2011). The relationship between adult attachment style and therapeutic alliance in individual psychotherapy: A meta-analytic review. Psychotherapy. Special Section: Attachment Style and Psychotherapy, 48, 237-248. https://doi.org/10.1037/a0022425

Digman, J. M. (1990). Personality structure: emergence of the five-factor model. Annual Review of Psychology, 41, 417-440. https://doi.org/10.1146/annurev.ps.41.020190.002221

Dozier, M. (1990). Treatment use for adults with serious psychopathological disorders. Development and Psychopathology, 2, 47-60. https://doi.org/10.1017/S0954579400000584

Dozier, M., Cue, K., \& Barnett, L. (1994). Clinicians as caregivers: Role of attachment organization in treatment. Journal of Consulting and Clinical Psychology, 62, 793-800.

Dutra, L., Stathopoulou, G., Basden, S. L., Leyro, T. M., Powers, M. B., \& Otto, M. W. (2008). A meta-analytic review of psychosocial interventions for substance use disorders. American Journal of Psychiatry, 165, 179-187. https://doi.org/10.1176/appi.ajp.2007.06111851

Eames, V., \& Roth, A. (2000). Patient attachment orientation and the early working alliance a study of patient and therapist reports of alliance quality and ruptures. Psychotherapy Research 10, 421-434. https://doi.org/10.1093/ptr/10.4.421

Elfström, M. L., Evans, C., Lundgren, J., Johansson, B., Hakeberg, M., \& Carlsson, S. G. (2013). Validation of the Swedish version of the Clinical Outcomes in Routine Evaluation Outcome Measure (CORE-OM). Clinical Psychological \& Psychotherapy, 20, 447-455. https://doi.org/10.1002/cpp.1788

Evans, C., Connell, J., Barkham, M., Margison, F., Mellor-Clark, J., McGrath, G., \& Audin, K. (2002). Towards a standardized brief outcome measure: psychometric properties and utility of the CORE-OM. British Journal of Psychiatry, 180, 51-60. https://doi.org/10.1192/bjp.180.1.51 
Falkenström, F., Granström, F., \& Holmqvist, R. (2013). Therapeutic alliance predicts symptomatic improvement session by session. Journal of Counselling Psychology, 60, 317-328. https://doi.org/10.1037/a0032258

Fletcher, K., Nutton, J., \& Brend, D. (2015). Attachment, a matter of substance: the potential of attachment theory in the treatment of addictions. Clinical Social Work Journal, 43, 109117. https://doi.org/10.1007/s10615-014-0502-5

Flückiger, C., Del Re, A. C., Horvath, A. O., Symonds, D., Ackert, M., \& Wampold, B. E. (2013). Substance use disorders and racial/ethnic minorities matter: a meta-analytic examination of the relation between alliance and outcome. Journal of Counseling Psychology, 60, 610-616. https://doi.org/10.1037/a0033161

Flückiger, C., Del Re, A. C., Wampold, B. E., Symonds, D., \& Horvath, A. O. (2012). How central is the alliance in psychotherapy? A multilevel longitudinal meta-analysis. Journal of Counseling Psychology, 59, 10-17. https://doi.org/10.1037/a0025749

Flückiger, C., Del Re, A. C., Wampold, B. E., \& Horvath, A.O. (2018). The alliance in adult psychotherapy: a meta-analytic synthesis. Psychotherapy, (Advance online publication). https://doi.org/10.1037/pst0000172

Flynn, P. M., Craddock, S. J., Luckey, J. W., Hubbard, R. L., \& Dunteman, G. H. (1996). Comorbidity of antisocial personality and mood disorders among psychoactive substancedependent treatment clients. Journal of Personality Disorders, 10, 56-67. https://doi.org/10.1521/pedi.1996.10.1.56

Fonagy, P., Gergely, G., Jurist, E., \& Target, M. (2002). Affect regulation, mentalization, and the development of the self. London, UK: Karnac.

Fonagy, P., Leigh, T., Steele, M., Steele, H., Kennedy, R., Mattoon, G., Target, M.,\& Gerber, A. (1996). The relation of attachment status, psychiatric classification, and response to psychotherapy. Journal of Consulting and Clinical Psychology, 64, 22-31. https://doi.org/10.1037/0022-006X.64.1.22

Fonagy, P., \& Allison, E. (2014). The role of mentalizing and epistemic trust in the therapeutic relationship. Psychotherapy, 51, 372-380. https://doi.org/10.1037/a0036505

Frederickson, J. (1999). Psychodynamic psychotherapy: Learning to listen from multiple perspectives. New York: Routledge.

Freud, S. (1912/1958). The dynamics of transference [Zur Dynamik der Übertragung]. (J. Starchey, Trans.). In J. Strachey (Ed.), The standard edition of the complete psychological works of Sigmund Freud (vol. 12, pp. 99-108). London: Hogarth Press.

Freud, S. (1913). On the beginning of treatment: Further recommendations on the technique of psychoanalysis [Zur Einleitung der Behandlung - Weitere Ratschläge zur Technik der Psychoanalyse]. In J. Strachey (Ed.), The standard edition of the complete psychological works of Sigmund Freud (vol. 12, pp. 122-144). London: Hogarth Press. 
Garner, B. R., Godley, S. H., \& Funk, R. R. (2008). Predictors of early therapeutic alliance among adolescents in substance abuse treatment. Journal of Psycho-Active Drugs, 40, 55 65. https://doi.org/10.1080/02791072.2008.10399761

George, C., Kaplan, N., \& Main, M. (1984). Adult attachment interview (1 ${ }^{\text {st }}$ ed.). Unpublished manuscript, Berkeley, CA: University of California at Berkeley.

George, C., Kaplan, N., \& Main, M. (1985). Adult attachment interview ( $2^{\text {nd }}$ ed.). Unpublished manuscript, Berkeley, CA: University of California at Berkeley.

George, C., Kaplan, N., \& Main, M. (1996). Adult attachment interview ( ${ }^{\text {rd }}$ ed.). Unpublished manuscript, Berkeley, CA: University of California at Berkeley.

Gielen, N., Havermans, R. C., Tekelenburg, M., \& Jansen, A. (2012). Prevalence of posttraumatic stress disorder among patients with substance use disorder: it is higher than clinicians think it is. European Journal of Psychotraumatology, 3:1.

https://doi.org/10.3402\%2Fejpt.v3i0.17734

Grant, B. F., Stinson, F. S., Dawson, D. A., Chou, S. P., Dufour, M. C., Compton, W., ... Kaplan, K. (2004). Prevalence and co-occurrence of substance use disorders and independent mood and anxiety disorders. Archives of General Psychiatry, 61, 807-816. https://doi.org/10.1001/archpsyc.61.8.807

Greenfield, S. F., Brooks, A. J, Gordon, S. M., Green, C. A., Kropp, F., McHugh, R. K., ..., Miele, G. M. (2007). Substance abuse treatment entry, retention, and outcome in women: A review of the literature. Drug and Alcohol Dependence, 86, 1-21. https://doi.org/10.1016/j.drugalcdep.2006.05.012

Greenson, R. R. (1965). The working alliance and the transference neuroses. Psychoanalysis Quarterly, 34, 155-181.

Gyllenhammar, C. (2012). KBT vid missbruk och beroende. In Fahlke C (Ed.). Handbok $i$ missbrukspsykologi. Malmö: Liber. (in Swedish)

Hatcher, R.L. \& Gillaspy, J.A. (2006). Development and validation of a revised short version of the Working Alliance Inventory. Psychotherapy Research, 16, 12-25. https://doi.org/10.1080/10503300500352500

Hazan, C., \& Shaver, P. R. (1987). Romantic love conceptualized as an attachment process. Journal of Personality and Social Psychology, 52, 511-524. https://doi.org/10.1037//0022-3514.52.3.511

Heilig, M. (2011). Beroendetillstånd. Lund: Studentlitteratur. (in Swedish)

Heilig, M. (2015). The thirteenth step: addiction in the age of brain science. New York: Columbia University Press. 
Hiebler-Ragger, M., Unterrainer, H. F., Rinner, A., \& Kapfhammer, H. P. (2016). Insecure attachment styles and increased borderline personality organization in substance use disorders. Psychopathology, 49, 341-344. https://doi.org/10.1159/000448177

Hoffmann, S. G., \& Barlow, D. H. (2014). Evidence-based psychological interventions and the common factors approach: the beginnings of a rapprochement? Psychotherapy, 51, 510-513. https://doi.org/10.1037/a0037045

Holmqvist, R., Ström, T., \& Foldemo, A. (2014). The effects of psychological treatment in primary care in Sweden - A practice-based study. Nordic Journal of Psychiatry, 68, 204212. https://doi.org/10.3109/08039488.2013.797023

Horvath, A. O., \& Bedi, R. P. (2002). The alliance. In J. C. Norcross (Ed.),Psychotherapy relationships that work. New York: Oxford

Horvath, A. O., Del Re, A. C., Flückiger, C., \& Symonds, D. (2011). Alliance in individual psychotherapy. Psychotherapy, 48, 9-16. https://doi.org/10.1037/a0022186

Hunt, G. M., \& Azrin, N. H. (1973). A community-reinforcement approach to alcoholism. Behaviour Research and Therapy, 11, 91-104. https://doi.org/10.1016/0005-7967(73)90072-7

Hussong, A. M., Jones, D. J., Stein, G. L., Baucom, D. H., \& Boeding, S. (2011). An internalizing pathway to alcohol use and disorder. Psychology of Addictive Behaviors, 25 , 390-404. https://doi.org/10.1037/a0024519

Jacobson, N. S., \& Truax, P. (1991). Clinical significance: A statistical approach to defining meaningful change in psychotherapy research. Journal of Consulting and Clinical Psychology, 59, 12-19. https://doi.org/10.1037/0022-006X.59.1.12

Jensen-Doss, A., \& Hawley, K. M. (2010). Understanding barriers to evidence-based assessment: clinician attitudes toward standardized assessment tools. Journal of Clinical Child and Adolescent Psychology, 39, 885-896. https://doi.org/10.1080/15374416.2010.517169

Joe, G. W., Simpson, D. D., \& Broome, K. M. (1998). Effects of readiness for drug abuse treatment on client retention and assessment of process. Addiction, 93, 1177-1190.

Kelly, T. M., Cornelius, J. R., \& Lynch, K. G. (2002). Psychiatric and substance use disorders as risk factors for attempted suicide among adolescents: A case-control study. Suicide and Life Threatening Behavior, 32, 301-309. https://doi.org/10.1521/suli.32.3.301.22168

Kelly, T. M., Daley, D. C., \& Douaihy, A. B. (2012). Treatment of substance abusing patients with comorbid psychiatric disorders. Addictive Behaviors, 37, 11-24.

https://doi.org/10.1016/j.addbeh.2011.09.010 
Kendler, K. S., Bulik, C. M., Silberg, J., Hettema, J. M., Myers, J., \& Prescott, C. A. (2000). Childhood sexual abuse and adult psychiatric and substance use disorders in women: an epidemiological and cotwin control analysis. Archives of General Psychiatry, 57, 953-959.

Kessler, R. C. (2004). Impact of substance abuse on the diagnosis, course, and treatment of mood disorders: The epidemiology of dual diagnosis. Biological Psychiatry, 56, 730-737. https://doi.org/10.1016/j.biopsych.2004.06.034

Khantzian, E. J. (1997). The self-medication hypothesis of substance use disorders: A reconsideration and recent applications. Harvard Review of Psychiatry, 4, 231-244. https://doi.org/10.3109/10673229709030550

Khantzian, E. J. (1985). The self-medication hypothesis of addictive disorders: focus on heroin and cocaine dependence. American Journal of Psychiatry, 142, 1259-1264. https://doi.org/10.1176/ajp.142.11.1259

Khantzian, E. J., \& Albanese, M. J. (2008). Understanding addiction as self medication: finding hope behind the pain. Maryland, USA: Rowman \& Littlefield Publishers, Inc.

Kushner, M. G. (2014). Seventy-five years of comorbidity research. Journal on Studies of Alcohol and Drugs, Supplement, 17, 50-58. https://doi.org/10.15288/jsads.2014.s17.50

Lambert, M. J., \& Barley, D. E. (2002). Research summary on therapeutic relationship and psychotherapy outcome. In J. C. Norcross (Ed.) Psychotherapy relationships that work: Therapist contributions and responsiveness to patients. New York, N.Y., Oxford University Press.

Lambert, M. J., \& Ogles, B. M. (2009). Using clinical significance in psychotherapy outcome research: The need for a common procedure and validity data. Psychotherapy Research, 19, 493-501. https://doi.org/10.1080/10503300902849483

Lambert, M. J. \& Shimokawa, K. (2011). Collecting client feedback. Psychotherapy, 48, $72-$ 79. https://doi.org/10.1037/a0022238

Langås, A. M., Malt, U. F., \& Opjordsmoen, S. (2012). Substance use disorders and comorbid mental disorders in first-time admitted patients from a catchment area. European Addiction Research, 18, 16-25. https://doi.org/10.1159/000332234

Lembke, A. (2012). Time to abandon the self-medication hypothesis in patients with psychiatric disorders. American Journal of Drug and Alcohol Abuse, 38, 524-529. https://doi.org/10.3109/00952990.2012.694532

Levy, K. N., Ellison, W. D., Scott, L. N., \& Bernecker, S. L. (2011). Attachment style. Journal of Clinical Psychology, 67, 193-203. https://doi.org/10.1002/jclp.20756

Lorenzo-Luaces, L., \& DeRubeis, R. J. (2018). Miles to go before we sleep: Advancing the understanding of psychotherapy by modeling complex processes. Cognitive Therapy Research, 42, 212-217. https://doi.org/10.1007/s10608-018-9893-x 
Luborsky, L. (1976). Helping alliances in psychotherapy. In J. L. Cleghhorn (Ed.), Successful psychotherapy (pp. 92-116). New York: Brunner/Mazel.

Luborsky, L., Barber, J. P., Sigueland, L., Johnson, S., Najavits, L. M., Frank, A., \& Daley, D. (1996). The revised helping alliance questionnaire (HAq-II): Psychometric properties. Journal of Pscyhotherapy Practice and Research, 5, 260-271.

Main, M. (1995). Recent studies in attachment: Overview, with selected implications for clinical work. In S. Goldberg, R. Muir \& J. Kerr (Eds.). Attachment theory: Social, developmental, and clinical perspectives (pp. 407-474). Hillsdale, NJ: The Analytic Press.

Main, M., \& Solomon J. (1986). Discovery of a new, insecure-disorganized/disoriented attachment pattern. In Yogman M. \& Brazelton T. B. (Eds.), Affective development in infancy (pp. 95-124). Norwood, NJ: Ablex.

Mallinckrodt, B. (2010). The psychotherapy relationship as attachment: Evidence and implications. Journal of Personal and Social Relationships, 27, 262-270. https://doi.org/10.1177/0265407509360905

Mallinckrodt, B., Gantt, D. L., \& Coble, H. M. (1995). Attachment patterns in the psychotherapy relationship: Development of the client attachment to therapist scale. Journal of Counseling Psychology, 42, 307-317. https://doi.org/10.1037/0022-0167.42.3.307

Margolese, J. C., Malchy, L., Negrete, J. C., Tempier, R., \& Gill, K. (2004). Drug and alcohol use among patients with schizophrenia and related psychoses: Levels and consequences. Schizophrenia Research, 67, 157-166. https://doi.org/10.1016/S0920-9964(02)00523-6

Marlatt, G.A. \& Donovan, D.M. (2005). Relapse prevention. Maintenance strategies in the treatment of addictive behaviors. New York: The Guilford Press.

Marmarosh, C. L., Gelso, C. J., Markin, R. D., Majors, R., Mallery, C., \& Choi, J. (2009). The real relationship in psychotherapy: relationships to adult attachments, working alliance, transference, and therapy outcome. Journal of Counseling Psychology, 56, 337-350. https://doi.org/10.1037/a0015169

Martin, D. J., Garske, J. P., \& Davis, K. M. (2000). Relation of the Therapeutic alliance with outcome and other variables: A meta analytic review. Journal of Clinical and Consulting Psychology, 68, 438-450.

McCauley, J. L., Killeen, T., Gros, D. F., Brady, K. T., \& Back. S. E. (2012). Posttraumatic stress disorder and co-occurring substance use disorders: Advances in assessment and treatment. Journal of Clinical Psychology, 19. https://doi.org/10.1111/cpsp.12006

McGue, M. (1999) The Behavioral genetics of alcoholism. Current Directions in Psychological Science, 8, 109-115. https://doi.org/10.1111\%2F1467-8721.00026 
McNemar, Q. (1957). Psychological statistics (2 ${ }^{\text {nd }}$ ed). New York: Wiley \& Sons Ltd. https://doi.org/10.1002/sce.37304103121

Meier, P. S., Barrowclough, C., \& Donmall, M. C. (2005a). The role of the therapeutic alliance in the treatment of substance misuse: a critical review of the literature. Addiction, 100, 304-316. https://doi.org/10.1111/j.1360-0443.2004.00935.x

Meier, P. S., Donmall, M. C., Barrowclough, C., McElduff, P., \& Heller, R. F. (2005b). Predicting the early therapeutic alliance in the treatment of drug misuse. Addiction, 100, 500-511. https://doi.org/10.1111/j.1360-0443.2005.01031.x

Mellor-Clark J., Barkham, M., Connell, J., \& Evans, C. (1999). Practice-based evidence and need for a standardized evaluation system: Informing the design of the CORE System. European Journal of Psychotherapy, Counseling and Health, 3, 357-374. https://doi.org/10.1080/13642539908400818

Mertens, J. R., Lu, Y. W., Parthasarathy, S., Moore, C., \& Weisner, C. M. (2003). Medical and psychiatric conditions of alcohol and drug treatment in an HMO: Comparison with matched controls. Archives of Internal Medicine, 163, 2511-2517. https://doi.org/10.1001/archinte.163.20.2511

Meyer, B., Pilkonis, P. A., Proietti, J. M., Heape, C. L., \& Egan, M. (2001). Attachment styles and personality disorders as predictors of symptom course. Journal of Personality Disorders, 15, 371-389. https://doi.org/10.1521/pedi.15.5.371.19200

Meyer, B., \& Pilkonis, P. A. (2002). Attachment style. In J. C. Norcross (Ed.), Psychotherapy relationships that work: Therapist contributions and responsiveness to patients ( $\mathrm{pp}$. 367382). London, UK: Oxford University Press.

Meyers, R.J. \& Miller, W.R. (Eds.) (2001). A Community Reinforcement Approach to Addiction Treatment. Cambridge: Cambridge University Press.

Mickelson, K. D., Kessler, R. C., \& Shaver, P. R. (1997). Adult attachment in a nationally representative sample. Journal of Personality and Social Psychology, 73, 1092-1106. https://doi.org/10.1037/0022-3514.73.5.1092

Mikulincer, M., \& Shaver, P. R. (2016). Attachment in adulthood: Structure, dynamics, and change (pp. 432-436). New York, NY: Guilford Press.

Mikulincer, M., Shaver, P. R., \& Berant, E. (2013). An attachment perspective on therapeutic processes and outcomes. Journal of Personality, 81, 606-616. https://doi.org/10.1111/j.1467-6494.2012.00806.x

Miller, W. R. (1983). Motivational interviewing with problem drinkers. Behavioural Psychotherapy, 11, 147-172. https://doi.org/10.1017/S0141347300006583

Miller, W. R., \& Rollnick, S. (1991). Motivational interviewing: Preparing people to change addictive behavior. New York: Guilford. 
Morisano, D., Babor, T. F., \& Robaina, K. A. (2014). Co-occurrence of substance use disorders with other psychiatric disorders: Implications for treatment services. Nordic Studies on Alcohol and Drugs, 31, 5-25. https://doi.org/10.2478/nsad-2014-0002

Mueser, K. T., Drake, R. E., \& Wallach, M. A. (1998). Dual diagnosis: a review of etiological theories. Addictive Behaviors, 23, 717-734.

Mueser, K. T., Noordsy, D. L., Drake, R. E., \& Fox. L. (2003). Integrated treatment for dual disorders: A guide to effective practice. New York, NY: Guilford Press.

Munder, T., Wilmers, F., Leonhart, R., Linster, H. W., \& Barth, J. (2010). Working Alliance Inventory-Short Revised (WAI-SR): psychometric properties in outpatients and inpatients. Clinical Psychology \& Psychotherapy, 17, 231-239. https://doi.org/10.1002/cpp.658

National Board of Health and Welfare (2017). (Socialstyrelsen in Swedish). Statistics on Causes of Death (Table 8). http://www.socialstyrelsen.se/publikationer2017/2017-9-11/

Norcross, J. C., \& Lambert, M. J. (2011). Evidence-based Therapy Relationships. In J. C. Norcross (Ed.) Psychotherapy relationships that work: Evidence-based responsiveness. Oxford Scholarship Online. https://doi.org/10.1093/acprof:oso/9780199737208.003.0001

Padykula, N. L., \& Conklin, P. (2010). The self regulation model of attachment trauma and addiction. Clinical Social Work Journal, 38, 351-360.

https://doi.org/10.1007/s10615-009-0204-6

Petry, N. M. (2000). A comprehensive guide to the application of contingency management in clinical settings. Drug and Alcohol Dependence, 58, 9-25.

Philips, B. (2009). Comparing apples and oranges: How do patient characteristics and treatment goals vary between different forms of psychotherapy? Psychology and Psychotherapy Theory Research and Practice, 82, 323-336. https://doi.org/10.1348/147608309X431491

Public Health Agency of Sweden. (Folkhälsomyndigheten in Swedish, statistics on web page): https://www.folkhalsomyndigheten.se/folkhalsorapportering-statistik/folkhalsansutveckling/halsa/narkotikarelaterad-dodlighet/ (in Swedish)

Quimette, P. C., Gima, K., Moos, R. H., \& Finney, J.W. (1999). A comparative evaluation of substance abuse treatment IV: The effect of comorbid psychiatric diagnoses on amount of treatment, continuing care and 1-year outcomes. Alcoholism: Clinical and Experimental Research, 23, 513-522.

Quimette, P. C., Read, J., \& Brown, P. J., (2005). Consistency of retrospective reports of DSM-IV criterion A traumatic stressors among substance use disorder patients. Journal of Traumatic Stress, 18, 43-51. https://doi.org/10.1002/jts.20009 
Ramstedt, M., Sundin, E:, Landberg, J., \& Raninen, J. (2014). ANDT-bruket och dess negativa konsekvenser i den svenska befolkningen 2013. Rapport nr.55. Stockholm: STAD. (in Swedish)

Regier, D. A., Farmer, M. E., Rae, D. S., Locke, B. Z., Keith, S. J., \& Judd, L. L. (1990). Comorbidity of mental disorders with alcohol and drug abuse. Journal of American Medical Association, 264, 2511-2518.

Reynolds, M., Mezey, G., Chapman, M., Wheeler, M., Drummond, C., \& Baldacchino, A. (2005). Co-morbid post-traumatic stress disorder in a substance misusing clinical population. Drug and Alcohol Dependence, 77, 251-258. https://doi.org/10.1016/j.drugalcdep.2004.08.017

Riggs, S. A., \& Jacobvitz, D. (2002). Expectant parents' representations of early attachment relationships: associations with mental health and family history. Journal of Consulting and Clinical Psychology, 70, 195-204.

Rogers, C. R., Gendlin, E. T., Kiesler, D. J., \& Truax, C. B. (1967). The therapeutic relationship and its impact: A study of psychotherapy with schizophrenics. Madison, WI: University of Wisconsin Press.

Roisman, G. I., Holland, A., Fortuna, K., Fraley, C., Clausell, E., \& Clarke, A. (2007). The adult attachment interview and self-reports of attachment style: An empirical rapprochement. Journal of Personality and Social Psychology, 92, 678-697. https://doi.org/10.1037/0022-3514.92.4.678

Rowe, C.L., Liddle, H.A., Greenbaum, P.E., Henderson, C.E. (2004). Impact of psychiatric comorbidity on treatment of adolescent drug abusers. Journal of Substance Abuse Treatment, 26, 129-140. https://doi.org/10.1016/S0740-5472(03)00166-1

Safran, J. D., \& Muran, J. C. (2000). Negotiating the therapeutic alliance: A relational treatment guide. New York: Guilford Press.

Safran, J. D., Muran, J. C., \& Eubanks-Carter, C. (2011). Repairing alliance ruptures. Psychotherapy, 48, 80-87. https://doi.org/10.1037/a0022140

Schindler, A., \& Bröning, S. (2015). A review on attachment and adolescent substance abuse: Empirical evidence and implications for prevention and treatment. Substance Abuse, 36, 304-313. https://doi.org/10.1080/08897077.2014.983586

Schindler, A., Thomasius, R., Petersen, K., \& Sack, P. M. (2009). Heroin as an attachment substitute? Differences in attachment representations between opioid, ecstasy and cannabis abusers. Attachment \& Human Development, 11, 307-330. https://doi.org/10.1080/14616730902815009 
Schindler, A., Thomasius, R., Sack, P. M., Gemeinhardt, B., Küstner, U., \& Eckert, J. (2005). Attachment and substance use disorders: a review of the literature and a study in drug dependent adolescents. Attachment \& Human Development, 7, 207-228. https://doi.org/10.1080/14616730500173918

Secades-Villa, R., \& Fernández-Hermida, J. R., (2003). The validity of self-reports in a follow-up study with drug addicts. Addictive Behaviors, 28, 1175-1182.

Shaver, P. R., Belsky, J., \& Brennan, K. A. (2000). The adult attachment interview and selfreports of romantic attachment: Associations across domains and methods. Personal Relationships, 7, 25-43. https://doi.org/10.1111/j.1475-6811.2000.tb00002.x

Sherwood Brown, E., Suppes, T., Adinoff, B., \& Rajan Thomas, N. (2001). Drug abuse and bipolar disorder: comorbidity or misdiagnosis? Journal of Affective Disorders, 65(2), 105115 .

Shimokawa, K., Lambert, M. J., \& Smart, D. W. (2010). Enhancing treatment outcome of patients at risk of treatment failure: meta-analytic and mega-analytic review of a psychotherapy quality assurance system. Journal of Consulting and Clinical Psychology, 78, 298-311. https://doi.org/10.1037/a0019247

Sinadinovic, K., Wennberg, P., \& Berman, A. H. (2014a). Short-term changes in substance use among problematic alcohol and drug users from a general population sample.

International Journal of Alcohol and Drug Research, 3, 277-287.

https://doi.org/10.7895/ijadr.v3i4.186

Sinadinovic, K., Wennberg, P., \& Berman, A. H. (2014b). Internet-based screening and brief intervention for illicit drug users: a randomized controlled trial with 12-month follow-up. Journal of Studies on Alcohol and Drugs, 75, 313-318. https://doi.org/10.15288/jsad.2014.75.313

Slade, A. (2016). Attachment and adult psychotherapy: Theory, research and practice. In J. Cassidy \& P. R. Shaver (Eds.), Handbook of attachment: Theory, research and clinical applications ( ${ }^{\text {rd }}$ ed.) (pp. 759-779). New York, NY: Guilford Press.

Socialstyrelsen (National Board of Health and Welfare). (2017). National guidelines for SUD treatment. (Nationella riktlinjer för vård och stöd vid missbruk och beroende). Stockholm: Socialstyrelsen.

https://www.socialstyrelsen.se/Lists/Artikelkatalog/Attachments/20778/2017-12-23.pdf (in Swedish)

SOU 2011:6 (2011). Missbruket, Kunskapen, Vården - Missbruksutredningens forskningsbilaga. [Abuse, Knowledge, Health Care - Official Report on Substance Abuse, research annex] http://www.regeringen.se/49b6a2/contentassets/e8736c3d067c4c45abf7a338b728f445/mis sbruket-kunskapen-varden-hela-dokumentet-sou-20116 (in Swedish) 
SOU 2011:35 (2011). Bättre insatser vid missbruk och beroende. [Better interventions for substance use disorders - Official Report] http://www.regeringen.se/49b6a2/contentassets/0c778ea424b749b89225617e54558413/bat tre-insatser-vid-missbruk-och-beroende-del-1-av-2-forord-och-kapitel-1-12-bilaga-1-5sou-201135 (in Swedish)

Swedish Agency for Health and Care Services Analysis (2016). Missar vi målen med missbruks- och beroendevården? Vårdanalys Rapport 2016:2. https://www.vardanalys.se/wp-content/uploads/2016/05/Missar-vi-m\%C3\%A5len-medmissbruks-och-beroendev\%C3\%A5rden-om-uppf\%C3\%B6ljning-av-resultat-ur-ettpatient-och-brukarperspektiv.pdf (in Swedish)

Sterba, R. F. (1934). The fate of the ego in analytic therapy. International Journal of Psychoanalysis, 115, 117-126.

Stewart, S.H. (1996). Alcohol abuse in individuals exposed to trauma: A critical review. Psychological Bulletin, 120, 83-112.

Sullivan, M. A., \& Rudnik-Levin, F. (2001). Attention deficit/hyperactivity disorder and substance abuse. Diagnostic and therapeutic considerations. Annals of the New York Academy of Science, 931, 251-270.

Talia, A., Daniel, S. I. F., Miller-Bottome, M., Brambilla, A., Miccoli, D., Safran, J. D., \& Lingiardi, V. (2014). AAI predicts patients' in-session interpersonal behavior and discourse: a "move to the level of the relation" for attachment-informed psychotherapy research. Attachment \& Human Development, 16, 192-209.

https://doi.org/10.1080/14616734.2013.859161

Talia, A., Miller-Bottome, M., \& Daniel, S. I. F. (2017). Assessing Attachment in Psychotherapy: Validation of the Patient Attachment Coding System (PACS). Clinical Psychology \& Psychotherapy, 24, 149-161. https://doi.org/10.1002/cpp.1990

Tasca, G. A., \& Lampard, A. M. (2012). Reciprocal influence of alliance to the group and outcome in day treatment for eating disorders. Journal of Counseling Psychology, 59, 507517. https://doi.org/10.1037/a0029947

Taubner, S., Klasen, J., \& Munder, T. (2016). Why do psychotherapists participate in psychotherapy research and why not? Results of the Attitudes to Psychotherapy Research Questionnaire with a sample of experienced German psychotherapists. Psychotherapy Research, 26, 318-331. https://doi.org/10.1080/10503307.2014.938256

Trolldal, B., \& Leifman, H. (2018). Alkoholkonsumtionen i Sverige 2017. CAN Rapport 175. https://www.can.se/contentassets/00aedc7994c94a34b2f35880ba8e1083/alkoholkonsumtio nen-i-sverige-2017_webb.pdf (in Swedish) 
Tryon, G. S., Blackwell, S. C., \& Hammel, E. F. (2007). A meta-analytic examination of client-therapist perspectives of the working alliance. Psychotherapy Research, 17, 629642. https://doi.org/10.1080/10503300701320611

Urbanoski, K. A., Kelly, J. F., Hoeppner, B. B., \& Slaymaker, V. (2012). The role of therapeutic alliance in substance use disorder treatment for young adults. Journal of Substance Abuse Treatment, 43, 344-351. https://doi.org/10.1016/j.jsat.2011.12.013

Urbanoski, K., Kenaszchuk, C., Veldhuizen, S., \& Rush, B. (2015). The clustering of psychopathology among adults seeking treatment for alcohol and drug addiction. Journal of Substance Abuse Treatment, 49, 21-26. https://doi.org/10.1016/j.jsat.2014.07.004

Van den Bosch, L. M. C., Verheul, R., Schippers, G. M., \& Van den Brink, W. (2002). Dialectical behavior therapy of borderline patients with and without substance use problems, implementation and long term effects. Addictive Behaviors, 27, 911-923. https://doi.org/10.1016/S0306-4603(02)00293-9

Van Emmerik-van Oortmerssen, K., Vedel, E., van den Brink, W., \& Schoevers, R.A. (2015). Integrated cognitive behavioral therapy for patients with substance use disorder and comorbid ADHD/ADD: two case presentations. Addictional Behavior, 45, 214-217. https://doi.org/10.1016/j.addbeh.2015.01.040

Volkow, N. D., Koob, G. F., \& McLellan, A. T. (2016). Neurobiologic advances from the brain disease model of addiction. New England Journal of Medicine, 374, 363-371. https://doi.org/10.1056/NEJMra1511480

Wallin, D. (2007). Attachment in psychotherapy. New York, NY: Guilford Press.

Waters, E., Merrick, S., Treboux, D., Crowell, J., \& Albersheim, L. (2000). Attachment security in infancy and early adulthood: A twenty-year longitudinal study. Child Development, 71, 684-689. https://doi.org/10.1111/1467-8624.00176

Wei, M., Russell, D. W., Mallinckrodt, B., \& Vogel, D. L. (2007). The Experiences in Close Relationship Scale (ECR) - short form: Reliability, validity, and factor structure. Journal of Personality Assessment, 88, 187-204. https://doi.org/10.1080/00223890701268041

Wennberg, P., Berglund, K., Berggren, U., Balldin, J., \& Fahlke, C. (2014). The Cloninger Type I/Type II typology: configurations and personality profiles in socially stable alcohol dependent patients. Advances in Psychiatry, Article ID 346157, 5 pages. http://dx.doi.org/10.1155/2014/346157

WHO (1992). The ICD-10 classification of mental and behavioural disorders: clinical descriptions and diagnostic guidelines, Geneva.

WHO (2018) http://www.who.int/mediacentre/factsheets/fs349/en/ 
Winters, K. C., Botzet, A. M., \& Fahnhorst, T. (2011). Advances in adolescent substance abuse treatment. Current Psychiatry Reports, 13, 416-421.

https://dx.doi.org/10.1007\%2Fs11920-011-0214-2

Winters, K. C., Stinchfield, R. D., Latimer, W. W., \& Stone, A. (2008). Internalizing and externalizing behaviors and their association with the treatment of adolescents with substance use disorder. Journal of Substance Abuse Treatment, 35, 269-278. https://doi.org/10.1016/j.jsat.2007.11.002

Wise, B. K., Cuffe, S. P., \& Fischer, T. (2001). Dual diagnosis and successful participation of adolescents in substance abuse treatment. Journal of Substance Abuse Treatment, 21, 161165.

Xu, H., \& Tracey, T. J. G. (2015). Reciprocal influence model of working alliance and therapeutic outcome over individual therapy course. Journal of Counseling Psychology, 62, 351-359. https://doi.org/10.1037/cou0000089

Yuodelis-Flores, C., \& Ries, R. K. (2015). Addiction and suicide: A review. The American Journal on Addictions, 24, 98-104. https://doi.org/10.1111/ajad.12185

Zack, S. E., Castonguay, L. G., Boswell, J. F., McAleavey, A. A., Adelman, R., Kraus, D. R., $\&$ Pate, G. A. (2015). Attachment history as a moderator of the alliance outcome relationship in adolescents. Psychotherapy, 52, 258-267. https://doi.org/10.1037/a0037727

Zetzel, E. R. (1956). Current concepts of transference. International Journal of Psychoanalysis, 37, 369-376.

Zilcha-Mano, S. (2017). Is the alliance really therapeutic? Revisiting this question in light of recent methodological advances. American Psychologist, 72, 311-325.

https://doi.org/10.1037/a0040435

Zilcha-Mano, S., Dinger, U., McCarthy, K. S., \& Barber, J. P. (2014). Does alliance predict symptoms throughout treatment, or is it the other way around? Journal of Consulting and Clinical Psychology, 82, 931-935. https://doi.org/10.1037/a0035141

Zubin, J., \& Spring, B. (1977). Vulnerability: A new view of schizophrenia. Journal of Abnormal Psychology, 86, 103-126. https://doi.org/10.1037/0021-843X.86.2.103

Zucker, R. A., Heitzeg, M. M., \& Nigg, J. T. (2011). Parsing the undercontrol/disinhibition pathway to substance use disorders: A multilevel developmental problem. Child Development Perspectives, 5, 248-255. https://doi.org/10.1111/j.1750-8606.2011.00172.x

Zuroff, D.C., Koestner, R., Moskowitz, D.S., McBride, C., Marshall, M., \& Bagby, M. R. (2007). Autonomous motivation for therapy: A new common factor in brief treatments for depression. Psychotherapy Research, 17, 137-147.

https://doi.org/10.1080/10503300600919380 
Öjehagen, A. (2011). Samsjuklighet mellan missbruk eller beroende och psykisk sjukdom. I: SOU 2011:6 Missbruket, kunskapen, vården - Missbruksutredningens forskningsbilaga, 223-235. [Comorbidity of substance use disorder and psychiatric disease] https://www.regeringen.se/contentassets/e8736c3d067c4c45abf7a338b728f445/missbruket -kunskapen-varden-hela-dokumentet-sou-20116 (accessed September 23, 2018) (in Swedish) 


\section{Appendix 1: The ICD-10 classification}

\section{Harmful use}

A pattern of psychoactive substance use that is causing damage to health. The damage may be physical (as in cases of hepatitis from the self-administration of injected drugs) or mental (e.g. episodes of depressive disorder secondary to heavy consumption of alcohol).

\section{Dependence syndrome}

A cluster of physiological, behavioral, and cognitive phenomena in which the use of a substance or a class of substances takes on a much higher priority for a given individual than other behaviors that once had greater value. A central descriptive characteristic of the dependence syndrome is the desire (often strong, sometimes overpowering) to take psychoactive drugs (which may or may not have been medically prescribed), alcohol, or tobacco. There may be evidence that a return to substance use after a period of abstinence leads to a more rapid reappearance of other features of the syndrome than occurs with nondependent individuals.

A definite diagnosis of dependence should usually be made only if three or more of the following have been present together at some time during the previous year:

1) a strong desire or sense of compulsion to take the substance;

2) difficulties in controlling substance-taking behavior in terms of its onset, termination, or levels of use;

3) a physiological withdrawal state when substance use has ceased or been reduced, as evidenced by: the characteristic withdrawal syndrome for the substance; or use of the same (or a closely related) substance with the intention of relieving or avoiding withdrawal symptoms;

4) evidence of tolerance, such that increased doses of the psychoactive substances are required in order to achieve effects originally produced by lower doses (clear examples of this are found in alcohol- and opiate-dependent individuals who may take daily doses sufficient to incapacitate or kill nontolerant users);

5) progressive neglect of alternative pleasures or interests because of psychoactive substance use, increased amount of time necessary to obtain or take the substance or to recover from its effects;

6) persisting with substance use despite clear evidence of overtly harmful consequences, such as harm to the liver through excessive drinking, depressive mood states consequent to periods of heavy substance use, or drug-related impairment of cognitive functioning; efforts should be made to determine that the user was actually, or could be expected to be, aware of the nature and extent of the harm. 


\section{Appendix 2: The DSM-IV classification}

\section{Substance abuse}

A. A maladaptive pattern of substance use leading to clinically significant impairment or distress, as manifested by one (or more) of the following, occurring within a 12-month period:

1. recurrent substance use resulting in a failure to fulfill major role obligations at work, school, or home (e.g., repeated absences or poor work performance related to substance use; substance-related absences, suspensions, or expulsions from school; neglect of children or household)

2. recurrent substance use in situations in which it is physically hazardous (e.g., driving an automobile or operating a machine when impaired by substance use)

3. recurrent substance-related legal problems (e.g., arrests for substance-related disorderly conduct)

4. continued substance use despite having persistent or recurrent social or interpersonal problems caused or exacerbated by the effects of the substance (e.g., arguments with spouse about consequences of intoxication, physical fights)

B. The symptoms have never met the criteria for substance dependence for this class of substance.

\section{Substance dependence}

A maladaptive pattern of substance use, leading to clinically significant impairment or distress, as manifested by three (or more) of the following, occurring at any time in the same 12-month period:

1. tolerance, as defined by either of the following:

a) a need for markedly increased amounts of the substance to achieve intoxication or desired effect

b) markedly diminished effect with continued use of the same amount of the substance

2. withdrawal, as manifested by either of the following:

a) the characteristic withdrawal syndrome for the substance

b) the same (or a closely related) substance is taken to relieve or avoid withdrawal symptoms

3. the substance is often taken in larger amounts or over a longer period than was intended

4. there is a persistent desire or unsuccessful efforts to cut down or control substance use

5. a great deal of time is spent in activities necessary to obtain the substance (e.g., visiting multiple doctors or driving long distances), use the substance (e.g. chain-smoking), or recover from its effects

6. important social, occupational, or recreational activities are given up or reduced because of substance use

7. the substance use is continued despite knowledge of having a persistent or recurrent physical or psychological problem that is likely to have been caused or exacerbated by the 
substance (e.g. current cocaine use despite recognition of cocaine-induced depression, or continued drinking despite recognition that an ulcer was made worse by alcohol consumption)

\section{Specify if:}

With physiological dependence: evidence of tolerance or withdrawal (i.e., either Item 1 or 2 is present)

Without physiological dependence: no evidence of tolerance or withdrawal (i.e., neither Item 1 nor 2 is present) 


\section{Appendix 3: The four attachment styles}

- prototypes cited from Bartholomew and Horowitz (1991):

"Secure: It is easy for me to become emotionally close to others. I am comfortable depending on others and having others depend on me. I don't worry about being alone or having others not accept me.

Preoccupied: I want to be completely emotionally intimate with others, but I often find that others are reluctant to get as close as I would like. I am uncomfortable being without close relationships, but I sometimes worry that others don't value me as much as I value them.

Dismissing: I am comfortable without close emotional relationships. It is very important to me to feel independent and self-sufficient, and I prefer not to depend on others or have others depend on me.

Fearful: I am uncomfortable getting close to others. I want emotionally close relationships, but I find it difficult to trust others completely, or to depend on them. I worry that I will be hurt if I allow myself to become too close to others." 


\section{Articles}

The articles associated with this thesis have been removed for copyright reasons. For more details about these see:

http://urn.kb.se/resolve?urn=urn:nbn:se:liu:diva-152443 